\section{Unión Latinoamericana de Extensión Universitaria: un espacio de cooperación, intercambio y reflexión en materia de extensión y vinculación con la sociedad}

Sylvia María Valenzuela Tovar

Miembro de la Unión Latinoamericana de

Extensión Universitaria.

Coordinadora académica Centro de

Formación, CEFNEC UNIMINUTO, Colombia.

sylviamaria.valenzuelatovar@gmail.com

RECEPCIÓN: 22/05/18

ACEPTACIÓN FINAL: 25/06/18

\begin{abstract}
Resumen
Hablar de escenarios de cooperación e intercambio académico e investigación en torno a la función de extensión universitaria supone una reflexión en el ámbito latinoamericano y caribeño. En este sentido, el presente artículo ha sido elaborado para compartir con los lectores de la revista una iniciativa regional que hoy completa 20 años de labores articulando múltiples actores, sectores y funciones sustantivas.

El texto presenta una breve síntesis de lo que es la extensión, proyección social o vinculación como función universitaria a fin de comprender el papel que desempeñan las redes académicas universitarias como mecanismos de cooperación. En este sentido, la Unión Latinoamericana de Extensión Universitaria (ULEU) surge como una estrategia regional de internacionalización de la educación superior que enfatiza en la misión social de la academia y la articulación de la investigación (a partir de la extensión) con las demás funciones universitarias. Como consecuencia, la ULEU influye favorablemente en los procesos educativos latinoamericanos aportando a investigaciones, políticas universitarias, oportunidades de formación, cooperación, e incluso construyendo nuevos saberes $y$ materiales bibliográficos, lo que la lleva hoy en día a afrontar nuevos desafíos.
\end{abstract}

Palabras clave: redes, extensión universitaria, internacionalización, Unión Latinoamericana de Extensión Universitaria
Latin american union of universitary change and reflection in matter of extension and link with society

\section{Abstract}

Talking about scenaries of cooperation and academic interchange and investigation around the function of universitary extension supposes a reflection in the latinoamerican and caribbean ambit.

In this sense the present article has been enarbolated in order to share with the magazine readers a regional initiative which completes twenty years of work, interchanging many actors,sectors and sustanctive functions.

The text presents a short synthesis about what extension, social projection or vinculation as an universitary function in order to understand the role that the academic universitary nets as cooperative mechanisms. In this sense, the latinoamerican union of universitary extension (ULEU) emerges as a regional strategy of internacionalization of the higher education which emphasizes the social mission of the academy and the articulation of the investigation ( from the extension ) with the other universitary functions. As a consequence, the ULEU influences favorably in the educational latinoamerican processes, contributing tobinvestigations, universitary politics, forming opportunities, cooperation and also building new knowledges and bibliographical, which now carries to face new challenges.

Keywords: networks, university extension, internationalization, Latin American University extension: a space of cooperation, interExtension Union
Investigación y extensión universitaria / Desafíos de gestión
União Latino-Americana de Extensão Universitária: um espaço de cooperação, intercâmbio e reflexão em termos de extensão e articulação com a sociedade

\section{Resumo}

O texto apresenta uma breve síntese do que é a extensão, projeção social ou articulação como função universitária, a fim de compreender o papel desempenhado pelas redes acadêmico-universitárias como mecanismos de cooperação. Nesse sentido, a União Latino-Americana de Extensão Universitária-ULEU surge como uma estratégia regional para a internacionalização do ensino superior, que enfatiza a missão social da academia e a articulação da pesquisa (da extensão) com as outras funções universitárias. Como consequência, a ULEU impacta positivamente nos processos educacionais latino-americanos contribuindo para a pesquisa, políticas universitárias, oportunidades de treinamento, cooperação e, até mesmo, construindo novos conhecimentos e materiais bibliográficos, o que a leva hoje a enfrentar novos desafios.

Palavras-chave: redes, extensão universitária, internacionalização, União Latino-Americana de Extensão Universitária

Para citación de este artículo: Valenzuela Tovar, S.M. (2018). Unión Latinoamericana de Extensión Universitaria: un espacio de cooperación, intercambio y reflexión en materia de extensión y vinculación con la sociedad. +E: Revista de Extensión Universitaria, 8(8), enero-junio, 61-88. doi: 10.14409/ extensión.v8i8.Ene-Jun.7720. 


\section{Introducción}

Al cumplirse 100 años de la Reforma de Córdoba, es posible hacer referencia a la extensión universitaria como herramienta de transformación social sostenida a partir de la relación dinámica de la universidad con las comunidades. De esta manera, la extensión, también llamada tercera función, se conoce hoy en algunos países latinoamericanos como proyección social, vinculación con el medio o relación universidad-sociedad. Podría decirse que a nivel regional, y de modo reciente, esta función universitaria se ha convertido en tema de reflexión y construcción académica para las Instituciones de Educación Superior (IES) latinoamericanas y caribeñas.

Al respecto, vale mencionar que cada nación, cada universidad y cada institución de educación superior posee su propia mirada, definición e interpretación de la extensión, y por lo tanto no es fácil encontrar parámetros universales o definiciones únicas que apliquen a todas las instituciones y lugares. Ahora bien, a nivel global existen coincidencias al presentar dicha función sustantiva e integradora como una posibilidad real de la academia para mejorar las condiciones de vida de los seres humanos al generar nuevos conocimientos, promocionar la diversidad cultural y aportar a la transferencia tecnológica que, como afirman Chacín et al., se dan al

"enriquecer las actividades de docentes y estudiantes, permitiéndoles abordar de manera más integral y eficiente los problemas, poniendo en evidencia nuevos ámbitos de trabajo e investigación al develar nuevas necesidades, carencias y fortalezas de la realidad en la cual se inserta". (2007:220)

Lo esencial, en todo caso, radica en pensar nuevos espacios y momentos fuera del aula y de los escenarios curriculares tradicionales para así fortalecer la formación integral desde una perspectiva investigativa que implica - entre otros aspectos- aprender haciendo, atar los contenidos académicos a significaciones culturales, éticas y estéticas, así como fortalecer la capacidad humana de la comunicación.

Podrían mencionarse los casos de Brasil, Uruguay, Argentina, Colombia y Cuba, entre otros, países han desarrollado su propia mirada crítica de la extensión universitaria, aclarando que en cada uno de ellos existe diversidad de miradas y teorías. Es así que varias universidades del norte de Brasil parten de una interpretación de la educación popular de Freire, mientras que Uruguay lo hace bajo la óptica dialógico-crítica. Por su parte, Argentina ${ }^{1}$ concibe dicha función universitaria como la misión que la universidad tiene de extender la vida académica y universitaria en su entorno geográfico, es decir, como la manera en la cual se concreta la responsabilidad de las universidades para apostar a la construcción social del conocimiento, las agendas de investigación orientadas a problemas relevantes con participación activa de los actores sociales, la incorporación de prácticas de educación experiencial, las intervenciones territoriales consensuadas con el Estado y los actores sociales.

Por otro lado, Colombia, de acuerdo con su legislación, la piensa como el grupo de programas de educación permanente que facilitan la difusión de los conocimientos, el intercambio de experiencias con la comunidad inter y extrauniversitaria, así como las actividades de

1) País que también cuenta con una gran variedad de posturas al respecto, las cuales van desde la denominación misma, las tradiciones y miradas político-institucionales, hasta los teóricos en quienes se apoyan. 
servicio. A ello se suma la interpretación emitida en 2008 durante la Declaración del Segundo Encuentro de Extensión Universitaria de la Asociación Colombiana de Universidades (ASCUN), que indica que "la extensión universitaria debe buscar y entenderse como procesos de interacción e integración con las comunidades". Finalmente, en el caso de Cuba, puede decirse que esta función es concebida como un sistema de interacciones universidad-sociedad realizado tanto al interior como al exterior de los centros educativos, con un énfasis especial en la cultura y el desarrollo territorial.

La extensión, entonces, no solo es relevante dentro de la academia por los motivos arriba expuestos sino que, adicionalmente, ofrece a las universidades la posibilidad de entender críticamente sus propias prácticas, repensarse institucionalmente y repensar sus políticas corporativas. ${ }^{2}$ Dado lo anterior, desde hace un tiempo la extensión universitaria latinoamericana y caribeña ha venido propiciando espacios de cooperación entre universidades, IES, estudiantes, docentes, graduados, administrativos, no docentes y comunidades en general a fin de aportar al mejoramiento de la educación superior, a las transformaciones sociales, económicas $\mathrm{y}$, por ende, a la calidad de vida de los seres humanos. Dichos espacios han puesto en evidencia el potencial de la extensión en los procesos formativos tanto para los estudiantes como para los docentes, graduados y personal administrativo.

Es aquí donde las redes universitarias ponen de manifiesto distintos modos de articulación con la sociedad que cada universidad lleva adelante. En esas articulaciones se expresan conocimientos, culturas, procesos, dinámicas, y se generan riquezas académico-formativas que, para el caso de la extensión universitaria, fortalecen los procesos de cooperación, intercambio y reflexión en la materia validando saberes y construyendo comunidad.

Así, el surgimiento y posicionamiento a nivel regional y latinoamericano de decenas de redes universitarias han llevado al trabajo conjunto, al desarrollo de agendas comunes, a la construcción de políticas compartidas y a la elaboración tanto de informes como de material académico relevante para el ejercicio de la extensión, proyección social o vinculación con el medio.

El presente artículo describe el papel de las redes académico-universitarias como mecanismos de cooperación. En un segundo momento realiza un recorrido histórico que concluye con el surgimiento de la Unión Latinoamericana de Extensión Universitaria (ULEU) como estrategia regional de internacionalización de la educación superior que enfatiza la misión social de la academia y la articulación de la investigación con las demás funciones universitarias. Posteriormente, presenta una síntesis del papel, impacto y resultados de la ULEU como red especializada que aporta investigaciones, material bibliográfico, políticas universitarias, oportunidades de formación y cooperación. Finalmente, se proponen algunas reflexiones y desafíos.

2) Las políticas corporativas universitarias constituyen el marco de referencia de cada institución de educación superior. Están compuestas por una serie de documentos, lineamientos y directrices referentes a la postura de la universidad frente a temas como la investigación, la docencia, la extensión o proyección social, el servicio al cliente, la innovación, la internacionalización, la formación y desarrollo profesorales, el bienestar institucional, la responsabilidad social, la gestión administrativa y financiera, entre otros. De esta manera, las universidades manifiestan su filosofía y declaran sus compromisos. 


\section{Redes académicas y universitarias como estrategias de cooperación}

Para Latinoamérica y el Caribe, la noción de red cobra cada día mayor relevancia al sugerir un trabajo conjunto, la suma de esfuerzos a favor de un ideal común, un intercambio de experiencias y una visibilidad regional a partir de la cual es posible el crecimiento y desarrollo conjunto de manera simultánea.

Las redes académicas, entendidas como sistemas de comunicación y como espacios políticos y de gestión, hacen referencia a colectivos o agrupación de docentes, estudiantes, graduados y funcionarios universitarios en calidad de delegados institucionales, quienes buscan en dichos escenarios colectivos el mejoramiento de la vida académica a fin de potenciar la internacionalización de la educación y la construcción de un proyecto común.

Para poder entender esta dinámica, es necesario partir del concepto de red que se adopta en el presente artículo. Para el caso que nos ocupa, el Instituto Internacional para la Educación Superior en América Latina y el Caribe (IESALC) de la Organización de las Naciones Unidas para la Educación, la Ciencia y la Cultura (UNESCO) sostiene:

"las redes contribuyen con los procesos de reflexión y acción concreta hacia la transformación de las instituciones y sistemas de Educación Superior de la región. Al exponer sus informaciones y estimular la cooperación, se facilita la potenciación de las fortalezas estratégicas que ellas tienen, reafirmando el papel fundamental de la Educación Superior como un bien público de interés permanente".

En esa medida, IESALC, consciente de la importancia de tales instancias y su influencia en los procesos de reflexión, acción y transformación de las instituciones y sistemas de educación superior regionales, ha creado un espacio dentro de su plataforma digital ${ }^{3}$, al cual ha denominado RedES de Educación Superior, como punto de referencia y visibilización de información, intercambio y participación de los diferentes actores. Bajo esta mirada de la UNESCO, las redes académicas universitarias son clasificadas según el tipo de trabajo que desarrollan las instituciones, la naturaleza temática de las mismas y, finalmente, de acuerdo con el nivel de cobertura, tal como se indica a continuación:

- Redes regionales: 18 registradas, las cuales se subdividen a la vez en intercontinentales, intrarregionales y subregionales.

- Redes nacionales: 46 subdivididas en consejos de rectores y asociaciones de instituciones de educación superior, organizaciones de apoyo y cooperación.

- Redes temáticas: 27 conformadas por asociaciones de la comunidad académica y organizaciones de investigación en educación superior.

- Redes, agencias y organismos internacionales: 20 registradas en la plataforma y conformadas por organizaciones internacionales de apoyo y cooperación con la educación superior y organizaciones internacionales.

Las primeras redes universitarias regionales, subregionales y nacionales prosperaron en América Latina a mediados del siglo XX como tendencia de la cooperación regional con di-

3) Información consultada en junio de 2018 en http://www.iesalc.unesco.org.ve/index.php?option=com_content\&view=article\&id=2360\%3Aenlaces-crea-un-espacio-para-la-redes-de-educacion-superior-de-america-latina-y-el-caribe\&catid=187\%3Adestacados\&ltemid=726\&lang=es 
ferentes fines y objetivos, siempre mostrando una marcada propensión al aseguramiento de la gestión de la calidad de la educación. De allí que, según la Declaración de la Conferencia Regional de la Educación Superior en América Latina y el Caribe (CRES) de 2008: "las redes académicas universitarias actúan de interlocutores ante los diferentes niveles de gobierno (...) y colaboran en la superación de las diferencias tanto nacionales como regionales" (12).

En consecuencia, la integración y asociación académica latinoamericanas pasan desde entonces a ser concebidas como una tarea necesaria e improrrogable de frente al futuro, desarrollo y crecimiento de la región con una mirada internacionalista de la educación superior.

El proceso de cooperación de las redes académico-universitarias se sustenta en el principio de la autonomía institucional, lo que lleva a los miembros que las conforman a trabajar por ideales comunes, implementando y respetando la diversidad de estrategias. Gracias al trabajo de estas redes se interconectan institucionalmente, se validan y promueven el aprendizaje, la innovación y la cultura. Las redes, por lo tanto, poseen carácter como agentes de cambio que dialogan críticamente y a la vez construyen conjuntamente el diseño de marcos comunes.

Desde allí decenas de universidades, organizaciones e instituciones ${ }^{4}$ de toda la región han encontrado en este esquema de trabajo una alternativa para los procesos de extensión, proyección social o vinculación. Y en este panorama internacional nace la ULEU como un espacio de cooperación, intercambio y reflexión en la materia que ofrece la creación de una agenda latinoamericana de extensión a fin de procurar una mejora en la educación de la región y el reconocimiento de un marco regional político para la función social universitaria.

\section{Nacimiento de la ULEU}

La ULEU ha sido, es y procura continuar como un espacio de relacionamiento y desarrollo regional a favor de la cooperación internacional entre universidades, instituciones, asociaciones y demás entidades cuya labor extensionista se realiza en virtud del desarrollo humano y social en escenarios educativos, productivos y comunitarios. De allí que, para poder entender su impacto y gestión, sea necesario remitirse a sus orígenes, hace poco más de 20 años.

El trabajo y existencia de la ULEU se remonta a la década de los '90, más exactamente al segundo semestre de 1993, momento en el cual un grupo de académicos extensionistas preocupados por evidenciar avances en materia de extensión universitaria organizó un encuentro internacional con el apoyo de los Ministerios de Educación de Cuba y Venezuela. Se trató del "Primer Encuentro Bilateral Cubano Venezolano de Directores de Cultura y Extensión Universitaria", que se llevó a cabo en la Universidad Camilo Cienfuegos de la ciudad de Matanzas, Cuba, del 12 al 20 de febrero de 1994.

\footnotetext{
4) Las instituciones poseen un carácter social y cooperativo que se rige por imposiciones legales que buscan determinar comportamientos de grupos sociales, trascendiendo voluntades individuales en pro de un bien social. En otras palabras, una institución es una entidad normativa jurídica y cultural soportada en leyes, ideales, creencias y valores como determinantes de una forma de intercambio social. Así pues, las instituciones intentan ordenar, legitimar y normalizar el comportamiento.

Entre tanto, las organizaciones son la concesión material de las instituciones, poseen estructuras administrativas a fin de conseguir metas u objetivos, es decir, se conforman con grupos en los cuales los individuos desempeñan diferentes roles y funciones mediante la gestión del talento humano. Están compuestas por personas naturales y jurídicas o administrativas con quienes producen bienes, servicios o normativas que satisfacen las necesidades de una comunidad en un entorno.
} 
En aquel evento, la reflexión propuesta y desarrollada por el grupo de asistentes giró en torno a la proyección social de las universidades, la cultura, la extensión y los contenidos culturales en los programas académicos universitarios. De manera puntual, se abordó la revisión de los perfiles de los trabajadores culturales, las políticas editoriales, las concepciones de cultura y de extensión, los modelos de planeamiento y de desarrollo cultural universitario y algunos enfoques de investigación con relación a áreas específicas de la actividad cultural.

Como conclusiones y acuerdos de ese primer encuentro y aproximación de agremiación universitaria, quedaron definidas una política de intercambio cultural, la creación de las cátedras José Martí y Simón Bolívar, el fortalecimiento de un proyecto editorial universitario, la promoción de intercambios interuniversitarios (tanto de docentes como de estudiantes) y la planificación de futuros eventos anuales con la intención de una progresiva incorporación de otros países latinoamericanos.

Dados los resultados y en pro del cumplimiento de los acuerdos, un año después (1995) en la Universidad de los Andes, Mérida, Venezuela, se realizó el "Segundo Encuentro Binacional de Directores de Cultura y Extensión Universitaria". En esa ocasión, la reflexión y diálogo se centraron en torno a la conceptualización de la extensión, las políticas y estrategias para su abordaje, algunas actividades de extensión y su incidencia en el ingreso-ascenso dentro del escalafón docente, así como en las estructuras organizativas de la misma, la valoración académica de dicha función y la extensión como oportunidad para fortalecer la integración latinoamericana. De igual forma, tanto asistentes como organizadores abrieron espacios de diálogo en cuanto a la función social de la extensión universitaria, las estrategias de participación de la comunidad en los programas o actividades extensionistas (al interior y exterior de los claustros) y el intercambio de actividades o prácticas de extensión como parte del plan de estudio en los diferentes pregrados.

Al encuentro asistió, por primera vez, una delegación de extensionistas, docentes e investigadores procedentes de Colombia, quienes representaban a la Universidad de Antioquia; la Universidad Escuela de Administración, Finanzas e Instituto Tecnológico de Medellín-EAFIT y la Universidad Pontificia Bolivariana. Finalizado el evento, se acordó celebrar en Cuba, al año siguiente, el "Tercer Encuentro Binacional de Directores de Cultura de Cuba y Venezuela", así como iniciar el trabajo de preparación para la creación de un organismo coordinador de la actividad extensionista universitaria en la región.

Sin embargo, no fue hasta el 7 de junio de 1996 en la Universidad de La Habana, Cuba, cuando se formalizó un trabajo mancomunado a la luz del I Encuentro Latinoamericano de Extensión Universitaria, más tarde conocido como CLEU, ${ }^{5}$ en el cual se promulgó la creación de un órgano integrador de proyectos y líneas de trabajo de la extensión universitaria latinoamericana, junto con la creación de un programa conjunto regional de extensión. En el marco del evento se reunieron para dialogar, reflexionar e intercambiar experiencias relacionadas con la concepción regional de la extensión universitaria, su promoción cultural, la formación integral y cultural del estudiante por las vías curriculares y extracurriculares; el movimiento artístico universitario, los medios de difusión y las cátedras honoríficas como elementos esenciales de la función de extensión universitaria. Este encuentro permitió el diálogo crítico 
frente a las estrategias de trabajo de extensión, el intercambio de investigaciones socioculturales y la realización de programas extensionistas para zonas tanto urbanas como rurales. Fruto del encuentro se ratificaron la política de intercambio cultural, las cátedras José Martí y Simón Bolívar, el proyecto editorial y la movilidad de docentes y estudiantes. También se estableció la planificación de nuevos eventos anuales para la mayor incorporación de países latinoamericanos y caribeños, sumada a la implementación de los acuerdos en las universidades de los países asistentes.

De este primer CLEU se resaltan los siguientes aspectos:

- Propuesta para la creación de una red latinoamericana en la cual estuvieran presentes las universidades asistentes al encuentro hasta la fecha, como vía de apoyo para los intercambios y acuerdos.

- Construcción de un banco de información para consultas de los extensionistas latinoamericanos y caribeños (manejado a través del correo electrónico).

- Formación de un Comité Permanente de trabajo responsable de coordinar, durante los tiempos entre eventos, el cumplimiento de los acuerdos y resoluciones aprobadas por la naciente red.

- Creación de un periódico digital para la sistematización y acceso a la información regional de las diferentes universidades miembros.

Por último, dicho congreso aportó a la extensión de la región su declaratoria final indicando en ella:

"La extensión, como ineludible vínculo de contenido ético que relaciona al hombre con su entorno social (...) la extensión universitaria como componente implícito de una óptima transcripción curricular de la docencia-investigación en la carrea universitaria". $\left(\right.$ ULEU, 1996) ${ }^{6}$

Estos encuentros y congresos continuaron desarrollándose de manera periódica. Por lo tanto, en noviembre de 1997, la Universidad Nacional de Cuyo, Mendoza, Argentina, realizó el II Encuentro Latinoamericano de Extensión Universitaria y el I Congreso Nacional de Extensión Universitaria, y para ello se propuso que el congreso sirviera de escenario de cooperación, reflexión e intercambio en torno a la relación de la educación superior con el sector público, el sistema económico productivo y la sociedad. Se trabajó ese año en los modos en que la extensión universitaria, proyección social o vinculación se estaba desarrollando en las universidades y de nuevo en la teoría y conceptualización de la extensión como función sustantiva integradora. En definitiva, la declaratoria de cierre estableció el fomento de redes regionales, zonales o nacionales en pro del intercambio de información a favor de la articulación de las instituciones universitarias, además del desarrollo de políticas extensionistas para la creación de un sistema nacional o sistema unificado regional.

Como continuación de los eventos, el equipo académico-extensionista que inició esta estrategia a favor de la extensión en la región llevó a cabo, en septiembre de 1998, el III CLEU 
bajo la denominación de III Congreso Iberoamericano ${ }^{7}$ y del Caribe de Extensión Universitaria, con sede en Costa Rica, pensando en ampliar el horizonte e incluir otras naciones. En esta ocasión, la Universidad Nacional de Heredia, como anfitriona, propuso el debate alrededor de las políticas y pertinencia de la extensión, la articulación de las funciones de docencia-investigación-extensión, la participación de la sociedad civil en asuntos locales, regionales y de gobierno, los avances tecnológicos y científicos de la extensión junto a la proyección social en los procesos formativos estudiantiles. Los asistentes también dialogaron en torno al carácter inter, multi y transdisciplinario de la extensión, la globalización con relación a la extensión universitaria y la educación continua. Al cierre del congreso se definió la creación de la Organización Iberoamericana y del Caribe de Extensión de la Educación Superior (OICEES) a fin de consolidar la función extensionista de manera que fuera posible aportar a la integración de las naciones y sus pueblos. La iniciativa tuvo gran acogida, pero no se concretó sino hasta finales del siguiente año y con algunos ajustes.

En octubre de 1999, la Universidad Pedagógica Experimental Libertador, de Venezuela, y el Núcleo de Directores de Cultura y Extensión de las universidades venezolanas organizaron un nuevo CLEU con mayor participación latinoamericana para trabajar sobre: la extensión y globalización, innovación extensionista, articulación de las funciones universitarias, pertinencia y vigencia de las políticas en extensión, formación de profesionales como agentes de transformación en las comunidades, importancia de la extensión en los currículos universitarios, financiamiento de la función, metodologías para la formulación de proyectos extensionistas y cooperación para el desarrollo de la extensión.

A diferencia de los congresos anteriores, este fue particularmente significativo porque se propuso en la declaración final la creación de la ULEU. Después de intensos debates y análisis de las declaraciones de los congresos precedentes y de una lectura sobre la situación regional, se decidió el pasaje de la creación de la OICEES a la ULEU, recuperando de este modo el carácter latinoamericano de la extensión.

Así, el 21 de octubre de 1999, como respuesta al desafío de pensar a la extensión como herramienta de transformación social a favor del bienestar de la ciudadanía, se creó la ULEU a manera de organización no gubernamental sin fines de lucro a partir de la presentación de su estatuto y el acta constitutiva de la red avalada por los asistentes de este último congreso. En su artículo 2 expresa:

"crear la Unión Latinoamericana de Extensión Universitaria, cuyo funcionamiento se base, por un lado, en el establecimiento de una red internacional de información entre instituciones de educación superior, entes gubernamentales y no gubernamentales, empresas públicas y privadas y sector laboral, que garantice un flujo dinámico de datos y divulgación de los planes, programas y proyectos de extensión universitaria. Por el otro, en el intercambio de experiencias mediante la realización de encuentros regionales, nacionales e internacionales, en donde se asegure el seguimiento a sus resoluciones y acuerdos y se

7) Con el fin de no limitar la participación en los congresos a aquellos países del continente americano (con excepción de Estados Unidos, Canadá, Surinam y Guyana) y teniendo en cuenta que en las versiones anteriores de los congresos se había contado con la asistencia de delegados procedentes de Brasil y España, a partir de 1998 la ULEU cambia la denominación de sus congresos latinoamericanos por la de congresos lberoamericanos conocidos desde entonces como CLEU. De esta manera, se amplía la posibilidad de inclusión y cooperación en los mismos a aquellos países de habla ibérica, es decir, Brasil, Portugal y España. 
plantee, discutan y aprueben nuevas proposiciones para el realizamiento permanente de la función de extensión". (ULEU, Declaración de Caracas, 1999:32)

La creación de la ULEU también significó una respuesta a la crisis continental educativa y social que se vivía por aquella época, así como una estrategia del grupo de docentes extensionistas e instituciones regionales que optaron por enfrentar el desafío de pensar a la extensión como medio de transformación social para el bienestar y desarrollo con una mirada dialógica y crítica.

\section{Trayectoria de la ULEU}

Como objetivos de la red, se pactó inicialmente propiciar el intercambio y debate científico respecto de temas de interés para la actividad extensionista. Además, se acordó aportar nuevas experiencias y propuestas de solución a los problemas relacionados con el entorno sociocultural universitario y el impacto social de sus acciones e intervenciones como red académica especializada. También se propuso realizar encuentros anuales para desarrollar el trabajo en red, avanzar en las discusiones y acuerdos tendientes a fortalecer la extensión universitaria. Por último, se decidió promover la socialización de buenas prácticas y gestionar actividades de internacionalización. Puntualmente y de manera especial, esta nueva red académica universitaria se enfocaría en la definición de líneas y estrategias tendientes a consolidar relación universidad-sociedad.

Con este gran paso dado, en noviembre del año 2000, la Asociación Nacional de Universidades e Instituciones de Educación Superior (ANUIES) convocó, a través de la Universidad de San Nicolás de Hidalgo, Michoacán, México, al V Encuentro Iberoamericano de Extensión, en el cual, además de abordar temas como las problemáticas de la extensión y sus programas, la necesidad de la relación universidad-sociedad, algunas estrategias de financiamiento para el desarrollo de la función extensionista, concluyó en su declaratoria final con la designación de un Consejo Directivo para la reciente Unión Latinoamericana de Extensión. Adicionalmente, estableció trabajar en una estrategia internacional de información entre las instituciones miembros de la Unión, bajo la responsabilidad de Brasil y México. Apoyar la realización del VI Congreso Iberoamericano de Extensión a desarrollarse en la Universidad Federal de São Paulo, Brasil, en 2001. Por último, convino que los próximos CLEU o Congresos Iberoamericanos de Extensión Universitaria se llevasen a cabo cada dos años. Sin embargo, las directivas y asamblea de la red, previendo un esfuerzo ya iniciado en torno a la preparación y realización del siguiente congreso iberoamericano, determinaron acatar el acuerdo de realización bianual a partir del año 2003.

En consecuencia, para noviembre de 2001, la Universidad Federal de São Paulo ofició de sede del VI Congreso Iberoamericano de Extensión Universitaria bajo el lema "Universidad y sociedad". Para ese entonces, organizadores, conferencistas y asistentes procedentes de Brasil, Bolivia, Colombia, Cuba, Ecuador, España, Guatemala, Honduras, México, Panamá, Uruguay y Venezuela, se reunieron para reflexionar acerca de: los derechos humanos, el medioambiente, la tecnología, cultura, comunicación, salud y educación; así como el trabajo, la sistematización y organización de la extensión. Como resultado adicional, los integrantes de la ULEU acordaron tramitar en Venezuela el registro de constitución legal de la red, 
consolidar una estructura organizativa y administrativa que facilitara la gestión de la Unión y un comité para la organización de los futuros CLEU independiente del Consejo Directivo de ULEU. Sumado a ello, se propuso buscar estrategias de financiamiento tendientes a facilitar la participación y afiliación a la red por parte de otros países e instituciones y se acordó iniciar el trabajo para la creación de una revista digital propia de esta reciente alianza.

Entre tanto, en septiembre de 2003, la Universidad Pinar del Río "Hermanos Saíz Montes de Oca", de la ciudad de Pinar del Río en Cuba, realizó el VII Congreso Iberoamericano de Extensión Universitaria bajo el lema "Extensión universitaria: opción viable por un mundo mejor". Al igual que en versiones anteriores, las temáticas fueron variadas, pero siempre permitiendo el diálogo, debate y construcción a favor de la extensión y comunicación, promoción de la salud y calidad de vida, relación universidad-sociedad, instrumentos metodológicos para la labor de la extensión universitaria; el trabajo comunitario desde la universidad, la gestión de la extensión universitaria, la promoción cultural desde las universidades y, por último, la extensión universitaria en lo curricular.

Dos años más tarde, en noviembre de 2005, en Brasil, la ULEU llevó a cabo el VIII Congreso Iberoamericano de Extensión Universitaria que tuvo como sede a la Universidad Federal de Rio de Janeiro. Como lema del encuentro se estableció "Navegar es necesario... transformar es posible", a fin de promover el análisis en cuanto a la cultura, los derechos humanos y la justicia, la tecnología y producción, salud y trabajo, evaluación de la extensión universitaria; comunicación y educación, organización y sistematización de la extensión universitaria y flexibilización curricular.

Luego de ese CLEU, Colombia fue sede por primera vez de un encuentro iberoamericano de extensión. En este ámbito, en noviembre de 2007, la Asociación Colombiana de Universidades (ASCUN) convocó en Bogotá al IX Congreso Iberoamericano de Extensión Universitaria / VI Encuentro Nacional de la Red de Extensión Universitaria bajo el lema "Gestión y evaluación de la extensión universitaria". Allí se abordaron el trabajo en red y la cooperación internacional, la gestión de la dimensión de la extensión, evaluación e indicadores de la dimensión de extensión y, por último, Responsabilidad Social Universitaria (RSU). Se destacó entonces en este encuentro la participación, por primera vez, de trabajos relacionados con la Responsabilidad Social Empresarial (RSE), la RSU y la extensión.

Fruto del congreso, al que asistieron más de 200 participantes en calidad de directivos, docentes y estudiantes de diferentes instituciones de educación superior de la región, se acordó que la universidad debía interactuar con la sociedad para compartir sus conocimientos de una manera mucho más dinámica y eficaz, al igual que trabajar con empeño por la institucionalización de la extensión tendiente a la definición de políticas a favor de su gestión y visibilización. Finalmente, se exhortó a trabajar desde la extensión universitaria implementando el "cuarteto de la I", es decir: impacto, interdisciplinariedad, interacción e indisolubilidad.

Años después y nuevamente con el apoyo de la ULEU, la Universidad de la República, Uruguay, organizó y desarrolló un nuevo congreso en su décima edición a partir del lema "Sociedad y extensión: hacia una universidad integrada y transformadora". En aquel entonces, tanto organizadores como asistentes trabajaron dialógica y críticamente en torno a cinco grandes ejes: universidad y pensamiento crítico; educación, sujetos colectivos y sectores populares; ciencia-sociedad y poder; soberanía alimentaria; economía, medios de comunicación y transformación social. 
Como resultado del debate, en la declaratoria final se convino concebir la extensión universitaria como una función ligada a los procesos de formación y producción de conocimientos que cumple un rol importante en la defensa de los derechos humanos. Adicionalmente, promover la participación de todos los actores de la comunidad universitaria en los CLEU y para ello ofrecer estrategias llamativas e incentivos (en especial para estudiantes), dado que hasta la fecha su participación no había sido significativa.

Llegado noviembre de 2011, en Santa Fe, Argentina, la Universidad Nacional del Litoral realizó el XI Congreso Iberoamericano de Extensión Universitaria bajo el lema "Integración extensión, docencia e investigación para la inclusión y la cohesión social”. Dicho congreso se destacó por haber contado con una participación superior a los 4000 asistentes procedentes de Latinoamérica, el Caribe, España y Portugal. Asimismo, estuvieron presentes los secretarios de Educación Superior de Cuba, Brasil, Argentina, Ecuador, y del Instituto Internacional para la Educación Superior en América Latina y el Caribe (IESALC).

Este congreso cobró una importancia especial en lo referente a la extensión como función universitaria latinoamericana y caribeña dado que, en el marco de su ejecución, nació la Revista $+E$ y se relanzó la ULEU. Lo primero, como una apuesta para pensar la integración de las tres funciones universitarias y crear un espacio de debate y reflexión en torno a las políticas de extensión del sistema universitario iberoamericano. Lo segundo, como estrategia de fortalecimiento para la red y reivindicación de su papel en la región. En ese momento la ULEU reformuló su estatuto y continuó su camino para trascender más allá de una red internacional de información entre instituciones de educación superior, entes gubernamentales y no gubernamentales, empresas públicas y privadas y sector laboral, que garantiza un flujo dinámico de datos y divulga los planes, programas y proyectos de extensión universitaria.

Al finalizar el CLEU y plenario de la ULEU, se acordó destacar su rol e importancia, trabajar para su consolidación y fortalecimiento como una red regional integrada por redes de carácter nacional e internacional. Propiciar el desarrollo de programas y proyectos de extensión universitaria en redes con el propósito de incrementar su impacto y auspiciar la movilidad de todos los involucrados. Potenciar la participación y protagonismo estudiantil extensionista como impulso dinamizador y transformador de las realidades sociales y educación superior desde una mirada crítica y comprometida. Desde entonces, quienes integran la ULEU desarrollaron con éxito y gran acogida otros tres Congresos iberoamericanos de Extensión Universitaria: Ecuador 2013, con el lema "La integración de la docencia, la investigación y la extensión para la transformación social"; La Habana, Cuba, 2015, titulado "La extensión universitaria promotora del cambio y la transformación sociocultural y el buen vivir"; y Nicaragua 2017 bajo el lema "Diálogo de saberes y conocimientos con compromiso social." Actualmente, la ULEU se encuentra preparando otros dos CLEU a realizarse en el año 2019 en Paraguay y en 2021 en Costa Rica.

A continuación, los Cuadros 1 y 2 sintetizan la relación de congresos latinoamericanos, iberoamericanos y caribeños de extensión universitaria realizados desde 1994 así como las temáticas de los mismos, los países convocantes y los principales acuerdos de cada uno. 
Cuadro 1. Síntesis de los congresos latinoamericanos y caribeños de extensión universitaria.

\begin{tabular}{|c|c|c|c|c|c|}
\hline Año/ fecha & $\begin{array}{l}\text { Lugar de } \\
\text { realización }\end{array}$ & $\begin{array}{l}\text { Número/ nombre } \\
\text { del congreso }\end{array}$ & Lema o tema central & Universidad sede & País/ instituciones convocantes \\
\hline $\begin{array}{l}12-20 \text { de } \\
\text { febrero de } \\
1994\end{array}$ & $\begin{array}{l}\text { Matanzas, } \\
\text { Cuba. }\end{array}$ & $\begin{array}{l}\text { Primer Encuentro Bilateral Cuba- } \\
\text { no Venezolano de Directores de } \\
\text { Cultura y Extensión Universitaria }\end{array}$ & & $\begin{array}{l}\text { Universidad "Camilo } \\
\text { Cienfuegos" de la } \\
\text { ciudad de Matanzas }\end{array}$ & Venezuela. \\
\hline $\begin{array}{l}\text { 3-8 de abril } \\
\text { de } 1995\end{array}$ & $\begin{array}{l}\text { Mérida, Vene- } \\
\text { zuela. }\end{array}$ & $\begin{array}{l}\text { Segundo Encuentro Binacional } \\
\text { de Directores de Cultura y Exten- } \\
\text { sión Universitaria }\end{array}$ & & $\begin{array}{l}\text { Universidad de los } \\
\text { Andes de Mérida }\end{array}$ & México, Cuba y Venezuela. \\
\hline $\begin{array}{l}5-7 \text { junio de } \\
1996\end{array}$ & $\begin{array}{l}\text { La Habana, } \\
\text { Cuba. }\end{array}$ & $\begin{array}{l}\text { I Encuentro Latinoamericano de } \\
\text { Extensión Universitaria }\end{array}$ & & $\begin{array}{l}\text { Universidad de la } \\
\text { Habana }\end{array}$ & Cuba. \\
\hline $\begin{array}{l}\text { 18- } 21 \\
\text { noviembre de } \\
1997\end{array}$ & $\begin{array}{l}\text { Mendoza, } \\
\text { Argentina. }\end{array}$ & $\begin{array}{l}\text { I Congreso Nacional de Extensión } \\
\text { y II Encuentro Latinoamericano } \\
\text { de Extensión Universitaria }\end{array}$ & & $\begin{array}{l}\text { Universidad Nacional } \\
\text { de Cuyo }\end{array}$ & $\begin{array}{l}\text { Argentina, Costa Rica, México, Venezuela y } \\
\text { Cuba. }\end{array}$ \\
\hline $\begin{array}{l}\text { Septiembre } \\
\text { 9-11 de } 1998\end{array}$ & $\begin{array}{l}\text { San José de } \\
\text { Costa Rica, } \\
\text { Costa Rica. }\end{array}$ & $\begin{array}{l}\text { III congreso Iberoamericano y del } \\
\text { Caribe de Extensión Universitaria }\end{array}$ & & $\begin{array}{l}\text { Universidad Nacional } \\
\text { de Heredia }\end{array}$ & $\begin{array}{l}\text { Costa Rica, Argentina, Cuba, México, Vene- } \\
\text { zuela y Chile. }\end{array}$ \\
\hline $\begin{array}{l}18-21 \text { de } \\
\text { octubre de } \\
1999\end{array}$ & $\begin{array}{l}\text { Caracas, } \\
\text { Venezuela. }\end{array}$ & $\begin{array}{l}\text { IV Congreso Iberoamericano y del } \\
\text { Caribe de Extensión Universitaria }\end{array}$ & & $\begin{array}{l}\text { Universidad Peda- } \\
\text { gógica Experimental, } \\
\text { Libertador }\end{array}$ & $\begin{array}{l}\text { Núcleo de Directores de Cultura y Extensión } \\
\text { de las Universidades Venezolanas. }\end{array}$ \\
\hline $\begin{array}{l}19-23 \text { de } \\
\text { noviembre de } \\
2000\end{array}$ & $\begin{array}{l}\text { Morelia, Mi- } \\
\text { choacán,Mé- } \\
\text { xico. }\end{array}$ & $\begin{array}{l}\text { V Congreso lberoamericano de } \\
\text { Extensión }\end{array}$ & $\begin{array}{l}\text { Sociedad, educación su- } \\
\text { perior y extensión: balance } \\
\text { y perspectivas. }\end{array}$ & $\begin{array}{l}\text { Universidad Michoa- } \\
\text { cana de San Nicolás } \\
\text { de Hidalgo }\end{array}$ & $\begin{array}{l}\text { ULEU y la Asociación Nacional de Universi- } \\
\text { dades e Instituciones de Educación Superior } \\
\text { (ANUIES, México). }\end{array}$ \\
\hline $\begin{array}{l}14 \text { al } 17 \text { de } \\
\text { noviembre de } \\
2001\end{array}$ & $\begin{array}{l}\text { São Paulo, } \\
\text { Brasil. }\end{array}$ & $\begin{array}{l}\text { VI Congreso Iberoamericano de } \\
\text { Extensión Universitaria }\end{array}$ & Universidad y sociedad. & $\begin{array}{l}\text { Universidad Federal } \\
\text { de São Pablo }\end{array}$ & ULEU y Brasil. \\
\hline $\begin{array}{l}22-26 \text { de } \\
\text { septiembre } \\
\text { de } 2003\end{array}$ & $\begin{array}{l}\text { Pinar del Río, } \\
\text { Cuba. }\end{array}$ & $\begin{array}{l}\text { VII Congreso Iberoamericano de } \\
\text { Extensión Universitaria }\end{array}$ & $\begin{array}{l}\text { Extensión universitaria: } \\
\text { opción viable por un } \\
\text { mundo mejor. }\end{array}$ & $\begin{array}{l}\text { Universidad de Pinar } \\
\text { del Río "Hermanos } \\
\text { Saiz Montes de Oca" }\end{array}$ & ULEU y Cuba. \\
\hline $\begin{array}{l}27-30 \text { de } \\
\text { noviembre de } \\
2005\end{array}$ & $\begin{array}{l}\text { Rio de Janeiro, } \\
\text { Brasil. }\end{array}$ & $\begin{array}{l}\text { VIII Congreso Iberoamericano de } \\
\text { Extensión Universitaria }\end{array}$ & $\begin{array}{l}\text { Navegar es necesario... } \\
\text { transformar es posible }\end{array}$ & $\begin{array}{l}\text { Universidade Federal } \\
\text { de Rio de Janeiro }\end{array}$ & ULEU y Brasil. \\
\hline $\begin{array}{l}7-9 \text { de } \\
\text { noviembre de } \\
2007\end{array}$ & $\begin{array}{l}\text { Bogotá, } \\
\text { Colombia. }\end{array}$ & $\begin{array}{l}\text { IX Congreso Iberoamericano } \\
\text { de Extensión Universitaria y VI } \\
\text { Encuentro Nacional de la Red de } \\
\text { Extensión Universitaria }\end{array}$ & $\begin{array}{l}\text { Gestión y evaluación de la } \\
\text { extensión universitaria }\end{array}$ & $\begin{array}{l}\text { Hotel equendama, } \\
\text { Bogotá. }\end{array}$ & $\begin{array}{l}\text { ULEU, la Asociación Colombiana de Universi- } \\
\text { dades (ASCUN), el Instituto Internacional para } \\
\text { la Educación Superior en América Latina y el } \\
\text { Caribe (IESALC/UNESCO). } \\
\text { EI Consejo Universitario Iberoamericano } \\
\text { (CUIB) y la Unión de Universidades de Améri- } \\
\text { ca Latina y el Caribe (UDUAL). }\end{array}$ \\
\hline $\begin{array}{l}5-9 \text { de octu- } \\
\text { bre de } 2009\end{array}$ & $\begin{array}{l}\text { Montevideo, } \\
\text { Uruguay. }\end{array}$ & $\begin{array}{l}\text { X Congreso Iberoamericano de } \\
\text { Extensión Universitaria-ExtenSo }\end{array}$ & $\begin{array}{l}\text { Sociedad y extensión: } \\
\text { hacia una universidad inte- } \\
\text { grada y transformadora. }\end{array}$ & $\begin{array}{l}\text { Universidad de la } \\
\text { República. }\end{array}$ & ULEU y la Universidad de la República. \\
\hline $\begin{array}{l}22-25 \text { de } \\
\text { noviembre de } \\
2011\end{array}$ & $\begin{array}{l}\text { Santa Fe, } \\
\text { Argentina. }\end{array}$ & $\begin{array}{l}\text { XI Congreso Iberoamericano de } \\
\text { Extensión Universitaria }\end{array}$ & $\begin{array}{l}\text { Integración extensión, do- } \\
\text { cencia e investigación para } \\
\text { la inclusión y la cohesión } \\
\text { social. }\end{array}$ & $\begin{array}{l}\text { Universidad Nacional } \\
\text { del Litoral. }\end{array}$ & ULEU y Argentina. \\
\hline $\begin{array}{l}19-22 \text { de } \\
\text { noviembre de } \\
2013\end{array}$ & $\begin{array}{l}\text { Quito, Ecua- } \\
\text { dor. }\end{array}$ & $\begin{array}{l}\text { XII Congreso Iberoamericano de } \\
\text { Extensión Universitaria }\end{array}$ & $\begin{array}{l}\text { La integración de la } \\
\text { docencia, la investigación } \\
\text { y la extensión para la } \\
\text { transformación social y el } \\
\text { buen vivir. }\end{array}$ & $\begin{array}{l}\text { Teatro universitario de } \\
\text { la Universidad Central } \\
\text { del Ecuador. }\end{array}$ & $\begin{array}{l}\text { ULEU, Universidad Central del Ecuador, la } \\
\text { Red Ecuatoriana Universitaria de Vinculación } \\
\text { de la Educación Superior (REUVIC), la Organi- } \\
\text { zación de la Naciones Unidas para la Educa- } \\
\text { ción - América Latina y el Caribe, (UNESCO/ } \\
\text { IESALC), el Consejo de Educación Superior } \\
\text { (CES), la Organización de Naciones Unidas } \\
\text { para la Agricultura y Alimentación (FAO) y el } \\
\text { Instituto Interamericano de Cooperación para } \\
\text { la Agricultura (IICA). }\end{array}$ \\
\hline $\begin{array}{l}\text { 1-4 de junio } \\
\text { de } 2015\end{array}$ & $\begin{array}{l}\text { La Habana, } \\
\text { Cuba. }\end{array}$ & $\begin{array}{l}\text { XIII Congreso Iberoamericano de } \\
\text { Extensión Universitaria. }\end{array}$ & $\begin{array}{l}\text { La extensión universitaria } \\
\text { promotora del cambio y } \\
\text { la transformación socio- } \\
\text { cultural. }\end{array}$ & $\begin{array}{l}\text { Palacio de Convencio- } \\
\text { nes de la Habana. }\end{array}$ & ULEU y Cuba. \\
\hline $\begin{array}{l}\text { 5- de junio de } \\
2017\end{array}$ & $\begin{array}{l}\text { Managua, } \\
\text { Nicaragua. }\end{array}$ & $\begin{array}{l}\text { XIV Congreso Latinoamericano y } \\
\text { del Caribe de Extensión Universi- } \\
\text { taria y el II Congreso Centroame- } \\
\text { ricano de Compromiso Social. }\end{array}$ & $\begin{array}{l}\text { Diálogo de saberes y } \\
\text { conocimientos con com- } \\
\text { promiso social. }\end{array}$ & $\begin{array}{l}\text { Centro de convencio- } \\
\text { nes Olof Palm. }\end{array}$ & $\begin{array}{l}\text { Nicaragua, Consejo Nacional de Universida- } \\
\text { des (CNU), ULEU y el Consejo Superior de } \\
\text { Universidades Centroamericanas (CSUCA). }\end{array}$ \\
\hline
\end{tabular}

Fuente: elaboración propia. 
Cuadro 2. Ejes temáticos, asistentes y acuerdos de los congresos latinoamericanos y caribeños de extensión universitaria.

\begin{tabular}{|c|c|c|c|c|}
\hline Año & $\begin{array}{l}\text { Numero/ nombre } \\
\text { del congreso }\end{array}$ & Principales acuerdos & Ejes temáticos & $\begin{array}{l}\text { Observaciones de } \\
\text { asistencia y participación }\end{array}$ \\
\hline 1994 & $\begin{array}{l}\text { Primer Encuentro Bilateral } \\
\text { Cubano Venezolano de } \\
\text { Directores de Cultura y } \\
\text { Extensión Universitaria }\end{array}$ & $\begin{array}{l}\text { 1. Creación de las cátedras José Martí y Simón } \\
\text { Bolívar a partir de la concepción básica de la } \\
\text { extensión como aplicación de los paradigmas } \\
\text { culturales del estudiante universitario. } \\
\text { 2. Definición de una política de intercambio } \\
\text { cultural y trabajo conjunto entre el Núcleo } \\
\text { de Cultura y Extensión de la Universidades } \\
\text { Venezolanas y el Ministerio de Educación } \\
\text { Superior de Cuba. } \\
\text { 3. Fortalecimiento de un proyecto editorial } \\
\text { universitario. } \\
\text { 4. Promoción de intercambios interuniversitarios } \\
\text { tanto de docentes como de estudiantes } \\
\text { 5. Planificación de futuros eventos anuales con } \\
\text { la intención de una progresiva incorporación de } \\
\text { otros países latinoamericanos. }\end{array}$ & $\begin{array}{l}\text { - Concepto de cultura y extensión. } \\
\text { - La proyección social de las universidades } \\
\text { - Los contenidos culturales en los programas } \\
\text { académicos universitarios. }\end{array}$ & \\
\hline 1995 & $\begin{array}{l}\text { Segundo Encuentro } \\
\text { Binacional de Directores } \\
\text { de Cultura y Extensión } \\
\text { Universitaria }\end{array}$ & $\begin{array}{l}\text { 1. Inicio del trabajo de preparación para la } \\
\text { creación de un organismo coordinador de la } \\
\text { actividad extensionista universitaria en la región } \\
\text { 2. Celebrar al siguiente año en Cuba, el tercer } \\
\text { encuentro Binacional de Directores de Cultura de } \\
\text { Cuba y Venezuela. }\end{array}$ & $\begin{array}{l}\text { - La extensión universitaria, su conceptuali- } \\
\text { zación: ¿Cultura y extensión? ¿Extensión y } \\
\text { cultura? } \\
\text { - Políticas y estrategias para abordar el ámbi- } \\
\text { to de la extensión universitaria. } \\
\text { - Estructuras organizativas de la extensión } \\
\text { universitaria. } \\
\text { - Las actividades de extensión y su incidencia } \\
\text { en el ingreso y ascenso escalafonario del } \\
\text { profesor universitario. } \\
\text { - Actividades de extensión como parte del } \\
\text { plan de estudio de las carreras universitarias: } \\
\text { su valoración académica. } \\
\text { - Función social de la extensión universitaria } \\
\text { - Estrategias de participación de la comuni- } \\
\text { dad intra y extra universitaria en las activida- } \\
\text { des de extensión. } \\
\text { - La extensión como oportunidad para fortale- } \\
\text { cer la integración latinoamericana. }\end{array}$ & $\begin{array}{l}\text { Participación de una delegación } \\
\text { de universidades de Colombia, } \\
\text { entre ellas, la Universidad de } \\
\text { Antioquia, Universidad Escuela } \\
\text { de Administración, Finanzas e } \\
\text { Instituto Tecnológico de Me- } \\
\text { dellín-EAFIT y la Universidad } \\
\text { Pontificia Bolivariana. }\end{array}$ \\
\hline 1996 & $\begin{array}{l}\text { I Encuentro Latinoa- } \\
\text { mericano de Extensión } \\
\text { Universitaria }\end{array}$ & $\begin{array}{l}\text { 1. Constituir un banco de información actualiza- } \\
\text { da que a través del correo electrónico pudiera } \\
\text { ser consultada. } \\
\text { 2. Formación de un comité permanente de traba- } \\
\text { jo que coordine, en el espacio entre cada evento, } \\
\text { el cumplimiento de los acuerdos y resoluciones } \\
\text { aprobadas. } \\
\text { 3. Creación de un periódico electrónico entre las } \\
\text { diferentes universidades latinoamericanas que } \\
\text { sistematice la posibilidad de acceso a la infor- } \\
\text { mación regional de las diferentes universidades } \\
\text { participantes. } \\
\text { 4. Seleccionar una universidad por cada país } \\
\text { que actúe como receptora de los canjes de los } \\
\text { fondos bibliográficos de las bibliotecas univer- } \\
\text { sitarias, como una vía para el conocimiento de } \\
\text { las realidades. } \\
\text { 5. Destaca que los seis temas que han funda- } \\
\text { mentado igual número de comisiones, converjan } \\
\text { en el planteamiento nodal acerca de las dicoto- } \\
\text { mías universidad-cultura, universidad-sociedad } \\
\text { y el debate sobre las disímiles aristas que } \\
\text { presuponen fijar el acto académico y su valida- } \\
\text { ción universal. } \\
\text { 6. Creación de algún órgano integrador de los } \\
\text { proyectos y líneas de trabajo de la extensión } \\
\text { universitaria latinoamericana, así como por la } \\
\text { elaboración de un Programa Latinoamericano } \\
\text { de Extensión. Proyectar la creación de una Red } \\
\text { Latinoamericana donde estén presentes las uni- } \\
\text { versidades que han asistido al Encuentro como } \\
\text { una vía para facilitar los intercambios. } \\
\text { 7. Se ratifica la política de intercambio cultural, } \\
\text { las cátedras José Martí y Simón Bolívar, el } \\
\text { proyecto editorial y la movilidad de docentes y } \\
\text { estudiantes. } \\
\text { 8. Establecimiento de la planificación de nuevos } \\
\text { eventos anuales para la mayor incorporación de } \\
\text { países latinoamericanos y caribeños, sumado a } \\
\text { la implementación de los acuerdos en las univer- } \\
\text { sidades de los países asistentes. }\end{array}$ & $\begin{array}{l}\text { - La formación cultural integral del estudiante } \\
\text { por las vías curricular y extracurricular. } \\
\text { - Estrategias de trabajo de la extensión uni- } \\
\text { versitaria en la labor intra y extramuros } \\
\text { - La promoción cultural en la extensión } \\
\text { universitaria. } \\
\text { - El movimiento artístico universitario: los } \\
\text { medios de difusión y las cátedras honoríficas } \\
\text { como elementos esenciales de la extensión } \\
\text { universitaria. } \\
\text { - Concepción actual de la extensión univer- } \\
\text { sitaria. } \\
\text { - Políticas para abordar la labor extensionista. } \\
\text { - Las investigaciones socioculturales y la } \\
\text { realización de programas en zonas rurales y } \\
\text { urbanas. }\end{array}$ & $\begin{array}{l}66 \text { universidades y represen- } \\
\text { tantes de } 11 \text { países. }\end{array}$ \\
\hline
\end{tabular}




\begin{tabular}{|c|c|c|c|c|}
\hline Año & $\begin{array}{l}\text { Numero/ nombre } \\
\text { del congreso }\end{array}$ & Principales acuerdos & Ejes temáticos & $\begin{array}{l}\text { Observaciones de } \\
\text { asistencia y participación }\end{array}$ \\
\hline 1997 & $\begin{array}{l}\text { I Congreso Nacional de } \\
\text { Extensión y II Encuentro } \\
\text { Latinoamericano de } \\
\text { Extensión Universitario }\end{array}$ & $\begin{array}{l}\text { 1. Se proponen una serie de objetivos para } \\
\text { viabilizar las relaciones de la educación superior } \\
\text { con el sistema económico productivo } \\
\text { 2. Auspiciar el desarrollo de una política nacio- } \\
\text { nal de extensión que prevea lineamientos de } \\
\text { evaluación, la incorporación curricular de las } \\
\text { prácticas extensionistas y la institucionalización } \\
\text { de la extensión en las instituciones de enseñanza } \\
\text { secundaria. }\end{array}$ & $\begin{array}{l}\text { - Relación de la educación superior con el } \\
\text { sistema económico productivo. } \\
\text { - Relación de le educación superior con la } \\
\text { sociedad y la cultura comunitaria. } \\
\text { - Relación de la educación superior con el } \\
\text { sector público: la extensión hacia el interior } \\
\text { de las instituciones. }\end{array}$ & $\begin{array}{l}\text { Instituciones de educación } \\
\text { superior y representantes } \\
\text { procedentes de Argentina, } \\
\text { Brasil, Costa Rica, México, } \\
\text { Venezuela, Cuba, Colombia, } \\
\text { Chile y España. }\end{array}$ \\
\hline 1998 & $\begin{array}{l}\text { III Congreso lberoame- } \\
\text { ricano y del Caribe de } \\
\text { Extensión Universitaria }\end{array}$ & $\begin{array}{l}\text { 1. Propuesta de creación de la Organización } \\
\text { Iberoamericana y del Caribe de Extensión de la } \\
\text { Educación Superior (OICEES) a fin de consolidar } \\
\text { la función extensionista y aportar a la integración } \\
\text { de las naciones y sus pueblos. }\end{array}$ & $\begin{array}{l}\text { - Políticas y pertinencia de la extensión. } \\
\text { - La articulación de las funciones de docen- } \\
\text { cia-investigación-extensión. } \\
\text { - Participación de la sociedad civil en asuntos } \\
\text { locales, regionales y de gobierno. } \\
\text { - Avances tecnológicos y científicos de la } \\
\text { extensión } \\
\text { - La extensión en los procesos formativos } \\
\text { estudiantiles. }\end{array}$ & $\begin{array}{l}\text { Participación especial de } \\
\text { España y Portugal por primera } \\
\text { vez. }\end{array}$ \\
\hline 1999 & $\begin{array}{l}\text { IV Congreso Iberoame- } \\
\text { ricano y del Caribe de } \\
\text { Extensión Universitaria }\end{array}$ & $\begin{array}{l}\text { 1. Declaración de Caracas, que entre sus } \\
\text { acuerdos incluye la propuesta de crear la Unión } \\
\text { Latinoamericana de Extensión Universitaria. } \\
\text { 2. Presentación del Acta Constitutiva y Estatutos } \\
\text { de la ULEU. }\end{array}$ & $\begin{array}{l}\text { - Extensión y globalización. } \\
\text { - Innovación extensionista. } \\
\text { - Articulación de las funciones universitarias. } \\
\text { - Pertinencia y vigencia de las políticas en } \\
\text { extensión. } \\
\text { - Importancia de la extensión-vinculación en } \\
\text { los currículos universitarios. } \\
\text { - Financiamiento de la función. } \\
\text { - Cooperación para el desarrollo de la ex- } \\
\text { tensión. } \\
\text { - La extensión en la formación de los pro- } \\
\text { fesionales universitarios como agentes de } \\
\text { cambio en la comunidad. } \\
\text { - La educación continua y la extensión } \\
\text { universitaria. } \\
\text { - Metodologías para la formulación y evaluaci- } \\
\text { ón de programas y proyectos de extensión. } \\
\text { - Estímulo y reconocimiento al desempeño } \\
\text { de la función de extensión. } \\
\text { - Gerencia de la extensión universitaria. } \\
\end{array}$ & $\begin{array}{l}\text { Realización de } 3 \text { conferencias } \\
\text { centrales, } 1 \text { foro, } 3 \text { talleres y } \\
\text { varias mesas de trabajo. }\end{array}$ \\
\hline 2000 & $\begin{array}{l}\text { V Congreso Iberoameri- } \\
\text { cano de Extensión }\end{array}$ & $\begin{array}{l}\text { 1. Operacionalizar las intenciones y propósitos } \\
\text { contenidos en el Acta Constitutiva y los Estatu- } \\
\text { tos de la Unión Latinoamericana de Extensión } \\
\text { Universitaria (ULEU). } \\
\text { 2. Designación de Consejo Directivo de la Unión } \\
\text { Latinoamericana de Extensión Universitaria } \\
\text { 3. Trabajar en una estrategia internacional de } \\
\text { información entre las instituciones miembros } \\
\text { de la Unión, bajo la responsabilidad de Brasil } \\
\text { y México. } \\
\text { 4. Apoyar la realización del VI Congreso lbero- } \\
\text { americano de Extensión en el 2001, con sede } \\
\text { en Brasil. } \\
\text { 5. Se acordó que los subsiguientes Congresos } \\
\text { Iberoamericanos de Extensión Universitaria se } \\
\text { realicen en forma bianual a partir de } 2003 \text {. } \\
\text { 6. Se recomendó, a objeto de perfeccionar el } \\
\text { estatuto de la Unión Latinoamericana de Exten- } \\
\text { sión, que las instituciones de educación supe- } \\
\text { rior enviaran a la presidencia de la Unión las } \\
\text { enmiendas respectivas, antes del } 30 \text { de marzo } \\
\text { del año } 2001 \text {. } \\
\text { 7. Permitir de manera masiva con los miembros } \\
\text { de la red, la socialización de trabajos investigati- } \\
\text { vos y experiencias de la extensión universitaria. }\end{array}$ & $\begin{array}{l}\text { - La extensión y la tecnología: una nueva } \\
\text { oportunidad. } \\
\text { - Extensión y sociedad: una relación nece- } \\
\text { saria. } \\
\text { • Estrategias de acción y financiamiento para } \\
\text { el desarrollo de la extensión. } \\
\text { - Bases para la construcción de un programa } \\
\text { estratégico para el desarrollo de la extensión } \\
\text { en las instituciones de educación superior } \\
\text { iberoamericanas. }\end{array}$ & $\begin{array}{l}\text { Participación de la OEI con } \\
\text { los siguientes especialistas: } \\
\text { Amparo Vilches (Universidad } \\
\text { de Valencia, España), Walter } \\
\text { Bazzo (Universidad de Florianó- } \\
\text { polis, Brasil), Hernán Verdugo } \\
\text { (Sociedad Chilena de profeso- } \\
\text { res de Ciencias, Chile). }\end{array}$ \\
\hline
\end{tabular}




\begin{tabular}{|c|c|c|c|c|}
\hline Año & $\begin{array}{l}\text { Numero/ nombre } \\
\text { del congreso }\end{array}$ & Principales acuerdos & Ejes temáticos & $\begin{array}{l}\text { Observaciones de } \\
\text { asistencia y participación }\end{array}$ \\
\hline 2001 & $\begin{array}{l}\text { VI Congreso Iberoa- } \\
\text { mericano de Extensión } \\
\text { Universitaria }\end{array}$ & $\begin{array}{l}\text { 1. Tramitar en Caracas el registro jurídico de la } \\
\text { ULEU. } \\
\text { 2. Consolidar la estructura organizativa y admi- } \\
\text { nistrativa que facilitará la gestión de la red. } \\
\text { 3. Conformar un Comité Organizador de los } \\
\text { Congresos independiente del Consejo Directivo } \\
\text { de la Unión. } \\
\text { 4. La Presidencia de la ULEU no debe girar sólo } \\
\text { alrededor de la organización de los eventos y } \\
\text { congresos. } \\
\text { 5. Necesidad de realizar reuniones ordinarias } \\
\text { de la red paralelamente a la realización de los } \\
\text { congresos. } \\
\text { 6. Buscar estrategias de financiamiento para } \\
\text { facilitar la afiliación de países e instituciones. } \\
\text { 7. Iniciar el trabajo para la creación de una revis- } \\
\text { ta digital propia de esta reciente red universitaria. }\end{array}$ & $\begin{array}{l}\text { - Comunicación. } \\
\text { - Cultura. } \\
\text { - Derechos Humanos. } \\
\text { - Educación. } \\
\text { - Medioambiente. } \\
\text { - Salud. } \\
\text { - Tecnología. } \\
\text { - Trabajo. } \\
\text { - Organización y sistematización. } \\
\text { - Extensión y programas interdisciplinares. }\end{array}$ & $\begin{array}{l}\text { Delegados de instituciones de } \\
\text { educación superior de Brasil, } \\
\text { Bolivia, Colombia, Cuba, } \\
\text { Ecuador, España, Guatemala, } \\
\text { Honduras, México, Panamá, } \\
\text { Uruguay y Venezuela. }\end{array}$ \\
\hline 2003 & $\begin{array}{l}\text { VII Congreso Iberoa- } \\
\text { mericano de Extensión } \\
\text { Universitaria }\end{array}$ & $\begin{array}{l}\text { 1. Creación de la página web de la Unión Latino- } \\
\text { americana de Extensión. }\end{array}$ & $\begin{array}{l}\text { - La gestión de la extensión universitaria. } \\
\text { - El trabajo comunitario desde la Universidad } \\
\text { - Extensión universitaria, Promoción de salud } \\
\text { y calidad de vida. } \\
\text { - Labor de promoción cultural desde las } \\
\text { Universidades. } \\
\text { - La extensión universitaria en lo curricular } \\
\text { - Relación Universidad-Sociedad. } \\
\text { - Instrumentos metodológicos para la labor de } \\
\text { extensión universitaria. } \\
\text { - Extensión y comunicación. }\end{array}$ & \\
\hline 2005 & $\begin{array}{l}\text { VIII Congreso Iberoa- } \\
\text { mericano de Extensión } \\
\text { Universitaria }\end{array}$ & & $\begin{array}{l}\text { - Evaluación de la extensión universitaria. } \\
\text { - Comunicación. } \\
\text { - Cultura. } \\
\text { - Derechos humanos y justicia. } \\
\text { - Educación y flexibilización curricular. } \\
\text { - Medioambiente. } \\
\text { - Organización y sistematización de la exten- } \\
\text { sión universitaria. } \\
\text { - Salud y trabajo. } \\
\text { - Tecnología y producción. }\end{array}$ & \\
\hline 2007 & $\begin{array}{l}\text { IX Congreso Iberoa- } \\
\text { mericano de Extensión } \\
\text { Universitaria y VI Encuen- } \\
\text { tro Nacional de la Red de } \\
\text { Extensión Universitaria }\end{array}$ & $\begin{array}{l}\text { 1. La universidad debe interactuar con la socie- } \\
\text { dad para compartir sus conocimientos de una } \\
\text { manera mucho más dinámica y eficaz. } \\
\text { 2. Trabajar con empeño por la institucionaliza- } \\
\text { ción de la extensión tendiente a la definición de } \\
\text { políticas a favor de su gestión y visibilización. } \\
\text { 3. Trabajar desde la extensión universitaria } \\
\text { implementando el "cuarteto de la l": impacto, in- } \\
\text { terdisciplinariedad, interacción e indisolubilidad. }\end{array}$ & $\begin{array}{l}\text { - Gestión de la dimensión de extensión. } \\
\text { - Responsabilidad Social Universitaria. } \\
\text { - Evaluación e indicadores de la dimensión } \\
\text { de extensión. } \\
\text { - El trabajo en red y la cooperación interna- } \\
\text { cional. }\end{array}$ & $\begin{array}{l}\text { Más de } 200 \text { participantes en } \\
\text { calidad de directivos, docentes } \\
\text { y estudiantes de diferentes } \\
\text { instituciones de educación } \\
\text { superior de la región. }\end{array}$ \\
\hline 2009 & $\begin{array}{l}\text { X Congreso } \\
\text { Iberoamericano de } \\
\text { Extensión Universitaria- } \\
\text { ExtenSo }\end{array}$ & $\begin{array}{l}\text { 1. Concebir a la extensión universitaria como } \\
\text { una función ligada a los procesos de formación } \\
\text { y producción de conocimientos que cumple un } \\
\text { rol importante en la defensa de los derechos } \\
\text { humanos. } \\
\text { 2. Promover la participación de todos los actores } \\
\text { de la comunidad universitaria en los CLEU y para } \\
\text { ello ofrecer estrategias llamativas e incentivos, } \\
\text { especialmente para los estudiantes. } \\
\text { 3. No habrá en adelante congresos iberoameri- } \\
\text { canos de extensión sin participación activa de } \\
\text { las organizaciones sociales y populares. } \\
\text { 4. Conformación del Comité Académico de } \\
\text { Extensión, bajo la iniciativa de la Asociación de } \\
\text { Universidades del Grupo Montevideo-AUGM. }\end{array}$ & $\begin{array}{l}\text { - Visión latinoamericana de Extensión. } \\
\text { - Prácticas integrales: articulación de Investi- } \\
\text { gación, enseñanza y extensión. } \\
\text { - Extensión, sociedad y territorio. } \\
\text { - Extensión y movimientos sociales. } \\
\text { - Formación: formación en Extensión; forma- } \\
\text { ción de formadores. }\end{array}$ & $\begin{array}{l}\text { Más de } 2.000 \text { estudiantes y } \\
\text { docentes latinoamericanos. }\end{array}$ \\
\hline
\end{tabular}




\begin{tabular}{|c|c|c|c|c|}
\hline Año & $\begin{array}{l}\text { Numero/ nombre } \\
\text { del congreso }\end{array}$ & Principales acuerdos & Ejes temáticos & $\begin{array}{l}\text { Observaciones de } \\
\text { asistencia y participación }\end{array}$ \\
\hline 2011 & $\begin{array}{l}\text { XI Congreso Iberoame- } \\
\text { ricano de Extensión } \\
\text { Universitaria }\end{array}$ & $\begin{array}{l}\text { 1. Destacar el rol e importancia de la ULEU en } \\
\text { la región. } \\
\text { 2. Trabajar para su consolidación y fortalecimien- } \\
\text { to como una red regional integrada por redes de } \\
\text { carácter nacional e internacional. } \\
\text { 3. Propiciar el desarrollo de programas y proyec- } \\
\text { tos de extensión universitaria en redes, con el } \\
\text { propósito de incrementar su impacto y auspiciar } \\
\text { la movilidad de todos los involucrados. } \\
\text { 4. Potenciar la participación y protagonismo } \\
\text { estudiantil extensionista como impulso dinami- } \\
\text { zador y transformador de las realidades sociales } \\
\text { y educación superior desde una mirada crítica y } \\
\text { comprometida. } \\
\text { 5. Surgimiento de la Revista +E, de la Univer- } \\
\text { sidad Nacional del Litoral, en versión impresa } \\
\text { y digital. } \\
\text { 6. Necesidad de reformular y actualizar los } \\
\text { estatutos de la ULEU. } \\
\text { 7. Fortalecer los lazos comunitarios con prác- } \\
\text { ticas participativas, el aprendizaje en servicio, } \\
\text { la construcción de ciudadanía, el rescate, la } \\
\text { valoración y la reflexión de historias, experien- } \\
\text { cias e identidades comunitarias, y la formación } \\
\text { en los criterios y metodologías de la investiga- } \\
\text { ción-acción. } \\
\text { 8. Promover la implementación de las resolucio- } \\
\text { nes y acuerdos emitidos por la ULEU, en cada } \\
\text { uno de los países de América Latina y el Caribe. } \\
\text { 9. Presentar en el marco de la reunión de Cuba } \\
\text { 2012, la propuesta temática, principios, linea- } \\
\text { mientos y estrategias a seguir para dar conti- } \\
\text { nuidad a los proyectos de la ULEU referentes } \\
\text { a página web y biblioteca virtual entre otros. } \\
\text { (Bajo la orientación y responsabilidad de la Red } \\
\text { Ecuatoriana Universitaria-REUVIC). }\end{array}$ & $\begin{array}{l}\text { - La investigación orientada a problemas } \\
\text { socialmente relevantes. } \\
\text { - La incorporación curricular de la extensión y } \\
\text { las acciones de transformación social. } \\
\text { - Políticas públicas. }\end{array}$ & $\begin{array}{l}\text { Participaron alrededor de } 5.000 \\
\text { docentes, estudiantes, gra- } \\
\text { duados y administrativos o no } \\
\text { docentes, de los cuales más de } \\
3500 \text { lo hicieron en calidad de } \\
\text { asistentes. } \\
\text { Incluyó } 1.151 \text { ponencias, } 654 \\
\text { pósters y más de } 120 \text { organiza- } \\
\text { ciones, } 50 \text { stands de emprendi- } \\
\text { mientos artísticos, artesanales } \\
\text { y culinarios; } 20 \text { editoriales } \\
\text { universitarias que presentaron } \\
\text { sus catálogos. } \\
\text { Contó con la presencia de } \\
\text { representantes de Francia, Mé- } \\
\text { xico, Guatemala, Costa Rica, } \\
\text { Venezuela, Colombia, Brasil, } \\
\text { Chile, Uruguay y Argentina., } \\
\text { además de España y Protugal. } \\
\text { El plenario de la Unión Lati- } \\
\text { noamericana de Extensión } \\
\text { Universitaria (ULEU) contó con } \\
\text { representantes de } 14 \text { países. }\end{array}$ \\
\hline 2013 & $\begin{array}{l}\text { XII Congreso Iberoa- } \\
\text { mericano de Extensión } \\
\text { Universitaria }\end{array}$ & $\begin{array}{l}\text { 1. Continuar trabajando en la actualización de } \\
\text { los estatutos de la ULEU. }\end{array}$ & $\begin{array}{l}\text { - Proyección latinoamericana de la extensión } \\
\text { universitaria. } \\
\text { - Transformación educativa desde la perspec- } \\
\text { tiva extensionista. } \\
\text { - Desarrollo local desde las contribuciones de } \\
\text { la extensión universitaria. } \\
\text { - Sociedad y territorio-extensión universitaria. } \\
\text { - Propuestas de transformación social: víncu- } \\
\text { los universidad-sociedad. } \\
\text { - Relación universidad-sociedad. }\end{array}$ & $\begin{array}{l}\text { Participación de más de } 1.000 \\
\text { especialistas en extensión } \\
\text { universitaria, provenientes de } \\
\text { diferentes instituciones de edu- } \\
\text { cación superior de } 10 \text { países de } \\
\text { América Latina y el Caribe. }\end{array}$ \\
\hline 2015 & $\begin{array}{l}\text { XIII Congreso Iberoa- } \\
\text { mericano de Extensión } \\
\text { Universitaria }\end{array}$ & $\begin{array}{l}\text { 1. Ratificar la contribución de las prácticas } \\
\text { artísticas y deportivas en la formación integral de } \\
\text { los futuros profesionales. } \\
\text { 2. Reafirmar el papel de la ULEU y su Congreso, } \\
\text { como espacio académico institucional de la } \\
\text { extensión más importante y representativo de las } \\
\text { universidades latinoamericanas y caribeñas. } \\
\text { 3. Retomar el carácter latinoamericano de la } \\
\text { extensión universitaria junto al de los congresos } \\
\text { a parir del próximo encuentro. }\end{array}$ & $\begin{array}{l}\text { - Políticas públicas de extensión universitaria. } \\
\text { - Gestión integrada de la extensión en su } \\
\text { vínculo con la docencia y la investigación. } \\
\text { - Universidad-sociedad: identidad y partici- } \\
\text { pación. } \\
\text { - Extensión y calidad: sistemas de evaluación. } \\
\text { - Actividad artística y deportiva universitaria e } \\
\text { inclusión social. } \\
\text { - Comunicación y extensión universitaria. } \\
\text { - La extensión universitaria por una cultura de } \\
\text { paz y equidad. } \\
\text { - Género, cultura y sociedad: El proyecto } \\
\text { sociocultural como eje de la gestión exten- } \\
\text { sionista. } \\
\text { - La extensión universitaria por un desarrollo } \\
\text { sostenible. }\end{array}$ & $\begin{array}{l}\text { Presencia de } 488 \text { delegados e } \\
\text { invitados de } 19 \text { países in- } \\
\text { cluyendo } 69 \text { estudiantes. } \\
\text { Presentación de } 489 \text { ponencias } \\
\text { en } 27 \text { talleres. Incluyó el de- } \\
\text { sarrollo de } 8 \text { conferencias, } 10 \\
\text { mesas redondas y paneles, así } \\
\text { como } 4 \text { sesiones de exposición } \\
\text { de póster. } \\
\text { Asistencia de } 357 \text { participantes } \\
\text { en los cursos-talleres ofre- } \\
\text { cidos. } \\
\text { Participación de } 135 \text { congre- } \\
\text { sistas extranjeros en las cinco } \\
\text { visitas especializadas a univer- } \\
\text { sidades de la capital. }\end{array}$ \\
\hline
\end{tabular}




\begin{tabular}{|c|c|c|c|c|}
\hline Año & $\begin{array}{l}\text { Numero/ nombre } \\
\text { del congreso }\end{array}$ & Principales acuerdos & Ejes temáticos & $\begin{array}{l}\text { Observaciones de } \\
\text { asistencia y participación }\end{array}$ \\
\hline 2017 & $\begin{array}{l}\text { XIV Congreso Latinoa- } \\
\text { mericano y del Caribe de } \\
\text { Extensión Universitaria y } \\
\text { el II Congreso Centroa- } \\
\text { mericano de Compromiso } \\
\text { Social }\end{array}$ & $\begin{array}{l}\text { 1. Conformación de un "Comité de Acción y } \\
\text { Seguimiento a los acuerdos" que, en acatamien- } \\
\text { to del principio de transparencia, informara sobre } \\
\text { el estado de avance de en cada caso con miras } \\
\text { a recuperar el liderazgo que la universidad debe } \\
\text { jugar en América Latina. } \\
\text { 2. Proponer que la extensión se convierta en } \\
\text { "guía política" de las universidades en función de } \\
\text { condicionar la formulación de los planes de es- } \\
\text { tudio y que oriente pertinentemente las agendas } \\
\text { de investigación y metodologías de construcción } \\
\text { y coproducción de conocimientos y saberes. } \\
\text { 3. Elevar al rango de actores de la extensión a } \\
\text { los integrantes de la comunidad universitaria en } \\
\text { su conjunto, desde la aceptación de la identidad } \\
\text { y la participación. } \\
\text { 4. Proponer un modelo de extensión universitaria } \\
\text { que se incline a la población más vulnerable } \\
\text { sin caer en un carácter de predomino asisten- } \\
\text { cialista a fin de que la comunidad universitaria } \\
\text { asuma procesos encaminados a la solución de } \\
\text { problemas concretos y que influyan en la trans- } \\
\text { formación social inclusiva, participativa y eman- } \\
\text { cipadora de nuestros pueblos en un sentido de } \\
\text { igualdad, equidad y justicia social. } \\
\text { 5. La extensión universitaria ha de ser una forma } \\
\text { de aprender integrada a un nuevo acto educativo } \\
\text { a lo largo de toda la formación de los estudian- } \\
\text { tes, comenzando desde el ingreso. }\end{array}$ & $\begin{array}{l}\text { - Universidades, Organizaciones Sociales y } \\
\text { Desarrollo Territorial. } \\
\text { - Jerarquización de la extensión universitaria } \\
\text { - Innovación, Desarrollo y Políticas Públicas } \\
\text { - Educación, Comunicación y Cultura } \\
\text { - Inclusión, Diversidad y Derechos Humanos. } \\
\text { - Integración Regional y procesos de Interna- } \\
\text { cionalización de la extensión universitaria. }\end{array}$ & $\begin{array}{l}\text { Cerca de } 700 \text { delegados exten- } \\
\text { sionistas de toda Latinoamérica } \\
\text { y el Caribe, en representación } \\
\text { de } 13 \text { países. } \\
\text { Asistencia de } 127 \text { congresistas } \\
\text { en las seis giras de campo } \\
\text { especializadas. } \\
\text { Participación de } 268 \text { personas } \\
\text { en los cursos (2) y cursos-talle- } \\
\text { res desarrollados (2). }\end{array}$ \\
\hline
\end{tabular}

Fuente: elaboración propia.

\section{Estructura y organización de la ULEU}

El actual estatuto ${ }^{8}$ de la ULEU presenta un equipo en red organizado de manera descentralizada, dado que los niveles de autoridad se encuentran representados en grupos circulares y cercanos con una figura central que actúa como líder máximo de la red a nivel latinoamericano y caribeño. Cada uno de estos grupos representa canales de gobierno y responsabilidad compartida, eliminando la idea de un estatus superior y garantizando el cumplimiento de los objetivos trazados. De esta manera, la ULEU cuenta con dos grandes órganos de gobierno y varias comisiones ${ }^{9}$ de trabajo. En cuanto a la sede administrativa de la red, esta posee un carácter itinerante y se radica bianualmente en el país de la institución o red del miembro a la que pertenezca el actual presidente.

La Asamblea general y el Comité Ejecutivo conforman sus principales órganos. La Asamblea es la máxima autoridad de la ULEU, sesiona una vez al año y se encuentra constituida por un representante legalmente acreditado de cada una de las redes, asociaciones u organismos miembros con el fin de elegir a los integrantes del Comité Ejecutivo, considerar y aprobar el plan anual de trabajo, conocer y aprobar los informes anuales de actividades

8) Aprobado en primera instancia en Quito, el 21 de noviembre de 2013 y en segunda y definitiva instancia en La Habana, el 12 de febrero de 2014 según los firmantes: presidencia de la ULEU (Ecuador); Red Nacional de Extensión universitaria de Argentina-REXUNI; Consejo Nacional de Universidades-CNU-Nicaragua, Universidad Nacional Agraria de Nicaragua, Ministerio de Educación Superior de Cuca-MES; Consejo Superior Universitario Centroamericano-SICAUS y CSUCA. foro de pro rectores de extensión-FORPROEX Brasil, Asociación de Universidades del Grupo Montevideo (AUGM), Red Ecuatoriana de Vinculación con la Colectividad (REUVIC) y la Universidad Bolivariana de Venezuela.

9) Comisión de comunicación, Comisión de elaboración del glosario de términos utilizados en Extensión Universitaria, Comisión de sistematización de los archivos y la documentación de la ULEU; Comisión de formación y capacitación en Extensión universitaria, Comisión de políticas para el financiamiento de la extensión universitaria. 
realizadas, auspiciar como red las actividades aprobadas en el plan de trabajo; definir criterios de admisión para las nuevas solicitudes de ingreso, aprobar los reglamentos internos propuestos por el Comité Ejecutivo, designar las comisiones de trabajo, modificar los estatutos y resolver cualquier situación no prevista.

Por su parte, el Comité Ejecutivo cuenta con un presidente, un vicepresidente y cuatro vocales, de los cuales la vicepresidencia es ejercida por el presidente saliente, la presidencia le corresponde al encargado de la coordinación y ejecución del próximo Congreso lberoamericano (CLEU) y las vocalías son elegidas por mayoría de voto. Esta instancia gobierna por un período de dos años y no permite reelección a fin de brindar la oportunidad a todos los miembros de la red. Como instancia organizativa se reúne de manera presencial al menos una vez por año y se encarga de implementar y desarrollar el plan de trabajo y otras actividades definidas por la asamblea general; favorecer la coordinación y comunicación entre los miembros de la ULEU; proponer a la asamblea general las orientaciones estratégicas de red; cumplir y hacer cumplir el estatuto y los reglamentos; elaborar el informe anual de actividades para presentar a la asamblea general; convocar a la asamblea ordinaria o extraordinaria; llevar las actas de las reuniones y resoluciones adoptadas por la asamblea y el comité; gestionar y administrar los recursos de ULEU y, finalmente, promover acciones de difusión.

Sumado a lo anterior, la ULEU cuenta con una Oficina Centro liderada desde Managua (Nicaragua) y una Oficina Sur liderada desde Rosario (Argentina), a través de las cuales se atienden solicitudes, agilizan procesos y apoya la aprobación de la utilización del logo o cualquier otro símbolo identitario de la ULEU para convocar o realizar actividades de cualquier índole por parte de los miembros.

En octubre de 2012, más fortalecida la red, se hizo realidad la propuesta formulada en noviembre de 2001 para la implementación de una nueva estrategia de trabajo conjunto regional: la revista digital de la ULEU titulada Identidad y territorio. Desde entonces, ya son 34 los números publicados. Y en febrero de ese mismo año la Asamblea de la red aprobó la creación de una comisión para la construcción de un glosario de términos empleados y relacionados con la extensión a nivel latinoamericano y caribeño. Para ello se asignó a los delegados de las Universidades Estatal Amazónica de la República de Ecuador (UEA) y de la Dirección de Extensión Universitaria del Ministerio de Educación Superior de la República de Cuba (MES), quienes algunos meses después (junio de 2015) presentaron ante la Asamblea de la ULEU el documento con el resultado del trabajo, el cual fue aprobado para su difusión.

"En tal sentido, el GULEU ${ }^{10}$ recoge, explica y comenta las palabras más utilizadas en la última década en la gestión universitaria extensionista para una mejor comprensión teórica y práctica de las mismas, lo cual facilita la comunicación y comprensión de los modelos seguidos por las universidades latinoamericanas y sus líneas priorizadas para el desarrollo, así como para la propia investigación científica que se genera como parte de la gestión cultural, innovadora, identitaria y participativa de dicho proceso; de igual modo, con el Glosario (...) se pretende fortalecer la comunicación científica entre las Instituciones de Educación Superior miembros de la ULEU”. (BEU, 2017: Glosario de términos de extensión universitaria) 
Sin embargo, con el pasar de los años, los logros obtenidos y los retos a enfrentar, los miembros de la ULEU, reunidos en noviembre de 2013 en Quito, retomaron la determinación en cuanto a la necesidad de realizar actualizaciones al estatuto inicial que les regía. Es así que, en febrero de 2014, en el marco del encuentro en La Habana, la asamblea realizó la nueva aprobación, ampliando sus horizontes y rangos de acción y también estableciendo nuevos objetivos para la red, entre ellos:

- Contribuir al mejoramiento de la calidad de la educación superior a través de la institucionalización de la extensión y su integración con la docencia y la investigación.

- Fomentar la unidad, la integración, el desarrollo sustentable y la solidaridad latinoamericana y caribeña a través del trabajo inter y transdisciplinario entre docentes, estudiantes, investigadores, gestores y la comunidad.

- Garantizar la continuidad de la realización de los Congresos Iberoamericanos de Extensión Universitaria, así como el cumplimiento de sus acuerdos.

- Propiciar la participación en congresos, encuentros y actividades de carácter científico, académico y de extensión universitaria que fortalezca los propósitos de la ULEU.

- Promover la creación y el fortalecimiento de las redes y/o asociaciones nacionales o regionales de extensión universitaria o sus equivalentes de instituciones de educación superior en países de América Latina y el Caribe.

- Favorecer el desarrollo y formación de recursos humanos en extensión universitaria de la educación superior.

- Implementar un sistema de comunicación que fortalezca las acciones de extensión universitaria de los miembros de la ULEU.

- Promover la internacionalización de la extensión universitaria en toda la región, sustentada en estrategias de movilidad y desarrollo conjunto de programas y proyectos.

Para ello, la ULEU se apoya en la responsabilidad y trabajo solidario de sus miembros, por lo cual su gestión se desarrolla a partir del trabajo solidario en red y no implica pago por la membresía pero sí compromiso de trabajo.

De esta manera, la ULEU, con su enfoque de la extensión dialógico-crítica, como espacio de cooperación, intercambio y reflexión en materia de vinculación con la sociedad, trabaja en la formación de ciudadanos integrales, el crecimiento cultural, y contribuye a elevar la calidad de vida de las poblaciones. Para ello busca que sean las mismas comunidades latinoamericanas y caribeñas las que, junto a la universidad, eduquen con un sentido totalmente humanizador, lo cual requiere contar con equipos interdisciplinarios de vocación transformadora compuestos por miembros de diferentes lugares, regiones y países. En esa medida, la extensión universitaria es entendida como una acción social con matriz en la docencia y la investigación, además de ser desarrollada como procesos dialógicos capaces de orientar tanto la enseñanza como la investigación de la región y alcanzar transformaciones sociales. Es aquí entonces donde cobra importancia el ir más allá del contexto inmediato, logrando que dichos equipos salgan de sus entornos, de sus zonas de confort, y lleguen a otros escenarios dentro de Latinoamérica y el Caribe. 
Como red académica universitaria que ha venido trabajando, aportando y progresando con los años, hoy la ULEU se encuentra conformada por un gran número de miembros ${ }^{11}$ pertenecientes a diferentes redes o asociaciones de extensión universitaria, universidades e instituciones de educación superior y sus equivalentes en diferentes países de América Latina y del Caribe; entre ellos, instituciones de Argentina, Bolivia, Brasil, Colombia, Costa Rica, Cuba, Ecuador, Guatemala, Honduras, México, Nicaragua, Panamá, Paraguay, República Dominicana, El Salvador, Uruguay y Venezuela. Es así que, casi 20 años después de su creación, la ULEU ha crecido en alianzas, ${ }^{12}$ miembros, logros y responsabilidades. Hoy se presenta como un espacio de vinculación, cooperación, intercambio y reflexión en materia de extensión universitaria de la educación superior, desde donde se afrontan diversos compromisos a favor de la formación extensionista, el crecimiento de la función, el desarrollo regional y mejoramiento de la calidad de vida. Para ello, soporta sus acciones en los principios de la autonomía institucional, la pertinencia, la identidad, la calidad, la justicia social, la solidaridad y la equidad.

En abril de 2018, luego de analizar el papel desempeñado por algunos miembros de la red en cada uno de sus lugares de procedencia, la asamblea aprobó la designación de un representante o enlace oficial de la ULEU para cada país, el cual es responsable de coordinar y acercar de forma directa las dudas o inquietudes que puedan generarse; garantizar la comunicación entre los miembros del país y la presidencia /vicepresidencia de la red; apoyar, asesorar y acompañar en extensión-proyección social a las IES de su país; visibilizar y divulgar de las acciones extensionistas del país a nivel latinoamericano y caribeño; recibir y canalizar las solicitudes de nuevos miembros o interesados; aprobar, junto con la presidencia y vicepresidencia de la ULEU, el uso del logo, nombre o cualquier otro símbolo de la red para convocar o realizar actividades de cualquier índole por parte de los miembros de su país.

\section{Internacionalización de la extensión a partir de la gestión de la ULEU}

El concepto mismo de internacionalización de la educación superior, entendido como el proceso mediante el cual se integran las funciones universitarias y los aspectos socioculturales a nivel internacional elevando la calidad educativa, conlleva, entre otros aspectos, a que las universidades y claustros universitarios se visibilicen en función del impacto social de sus acciones en la región. Implica determinada movilidad académica de estudiantes, docentes, gestores y administrativos; movilidad de redes internacionales, asociaciones y proyectos; construcción de nuevos programas e investigaciones. Supone la investigación y actualización constante en las tendencias y metodologías de enseñanza-aprendizaje, entre otras cuestiones.

Para el IESALC, a través de Jane Knight, la internacionalización de la educación posee diferentes caras e interpretaciones de acuerdo con los actores, sus instituciones y países.

11) Se trata de 17 países, 22 instituciones, 13 redes regionales, más de 66 delegados internacionales, alrededor de 2000 seguidores en redes sociales y más de 60000 seguidores de su sitio web.

12) Nexos y relaciones interinstitucionales con más de 100 universidades públicas y varias privadas de Latinoamérica, organismos gubernamentales, entes regionales y nacionales, así como redes y gobiernos. 
Podría decirse entonces que tal concepto es entendido como:

"la transmisión de educación a otros países, a través de nuevas disposiciones, como las sucursales de universidades o franquicias, usando una variedad de técnicas cara-a-cara y a distancia (...) significa la inclusión de una dimensión internacional, intercultural y/o global dentro del curriculum y el proceso de enseñanza-aprendizaje”. (Knight, 2010:s/n)

En consecuencia, el camino que conduce a la internacionalización de la educación, y por ende de la extensión universitaria, acarrea aspectos como:

a) Generación de una forma de pensamiento globalizado al interior de los centros educativos como herramienta de gestión y proceso transversal universitario, en el cual todos los actores cumplen un rol indispensable dado lo mucho que tienen para aportar.

b) Fomento de grupos, asociaciones o redes como espacios de cooperación, reflexión, intercambio y construcción.

c) Desarrollo de relaciones interinstitucionales con diferentes actores locales, regionales e internaciones acoplados por los mismos objetivos.

d) Establecimiento y creación de vías académicas, investigativas y extensionistas de intercambio de alto nivel.

e) Facilidad y acceso a múltiples culturas, historias e idiomas.

Es en este escenario globalizado de internacionalización que las redes académicas universitarias cumplen un rol fundamental al facilitar a las universidades latinoamericanas alinear estrategias y desarrollar acciones conjuntas a favor de la calidad misma de la educación. Para quienes son parte de la ULEU, los beneficios obtenidos a través de esta alianza son innumerables, no solo reciben las ventajas propias de las redes académicas universitarias y de la internacionalización, sino que gracias a ella las instituciones, universidades, entidades o subredes que la conforman tienen la posibilidad de asistir, compartir e intercambiar experiencias a través de los encuentros latinoamericanos, regionales e internacionales anuales especializados en la materia.

Como miembros oficiales, sus integrantes pueden publicar en la revista digital propia de la red -ldentidad y territorio-, hallar con material académico e investigativo especializado, publicar en revistas de extensión internacionales, ${ }^{13}$ contar con espacios latinoamericanos y caribeños de socialización para casos exitosos y buenas prácticas. Además de participar en proyectos de investigación, académicos y de cooperación internacional, acceder permanentemente a información, eventos, proyectos y tendencias en torno a la vinculación de las universidades con la sociedad.

Sumado a estas cuestiones, la ULEU aporta a los procesos de internacionalización de la extensión de las universidades miembro al ofrecer la posibilidad de participar en escuelas de verano y diplomados de extensión-proyección social, disfrutar del relacionamiento con otras redes de extensión universitaria regionales o nacionales, tener apoyo en formación a gestores extensionistas, acudir a una amplia red de pares evaluadores y expertos en la ma-

13) Entre ellas, las revistas: + E en sus versiones digital e impresa, Universidad en Diálogo, revista Masquedós, revista ExtendER, EXT y Redes. Revista de Extensión (siguiendo los requisitos y parámetros establecidos en cada una de ellas). 
teria. A su vez, la ULEU colabora y participa en el programa radial de la red, ${ }^{14}$ denominado "Integrados" (que coordina el programa de comunicación de la Universidad de Nacional de Avellaneda, Argentina), y finalmente, respalda la organización y desarrollo de eventos institucionales, así como visibiliza a las instituciones, sus acciones e impactos.

Gracias al trabajo conjunto y solidario de todos sus miembros, con el pasar de los años la Unión ha desarrollado e institucionalizado en la región, de manera adicional a los CLEU, una serie de eventos y encuentros enfocados en el ejercicio y crecimiento de la extensión universitaria, proyección social, vinculación con el medio y vinculación con la sociedad entre los cuales son posibles de mencionar, por ejemplo:

- Las jornadas de extensión de Latinoamérica.

- Los congresos nacionales de extensión universitaria.

- Las jornadas de extensión del Mercosur.

- Los congresos centroamericanos de compromiso social.

- Los congresos internacionales de educación superior.

- Las escuelas de verano con énfasis en extensión.

- Los talleres internacionales de extensión universitaria.

- Las misiones universitarias internacionales.

- Los diplomados en gestión y fortalecimiento de la extensión universitaria.

- Los seminarios latinoamericanos de investigación, entre otros.

Por otra parte, un aporte significativo de la ULEU es el avance hacia una mayor institucionalización y reconocimiento académico de la extensión universitaria y la apuesta a la integración de funciones. Estas premisas están presentes en las diferentes agendas territoriales, lo que permite pensar y trabajar en la adecuación de políticas públicas al respecto. De esta manera, la contribución de la ULEU no solo permite evidenciar y vivir de cerca ejemplos claros de articulación de las funciones universitarias, sino también, acceder a materiales académicos, investigaciones, contar con líneas de comunicación y evaluación de la extensión, dar cuenta de la diversidad de perspectivas en cuanto a extensión, proyección social y vinculación.

Asimismo, la ULEU se destaca en la región como un espacio de cooperación, intercambio y reflexión desde donde se producen publicaciones seriales, se ofrece una biblioteca digital de extensión universitaria, se brinda al público en general la serie de libros titulados LoS caminos de la extensión, se comparte la elaboración de glosarios de términos con relación a la extensión y una serie de cuadernillos de extensión universitaria, entre otras cuestiones.

Como corolario de todo este proceso, la ULEU ha tenido gran impacto en los procesos educativos, sociales y universitarios de América Latina durante los últimos 20 años. Ha crecido académicamente, en miembros y presencia en la región, gracias a las diferentes asociaciones de extensión universitaria, países, universidades e instituciones de educación superior y subredes que la conforman. Con ello se propicia la participación institucional en congresos,

14) Aprobado por la Asamblea plenaria de la red, el 25 de abril de 2018 en Tandil, Argentina. El programa busca contener y albergar las múltiples producciones realizadas en el área de docencia, investigación y extensión en el ámbito de la ULEU, e impulsar a su vez, la producción y divulgación de conocimiento en el área de la extensión universitaria. Para ello brinda la posibilidad a cada integrante de la ULEU de tener representación con una corresponsalía, encargada de producir el material para el programa. Dicho mecanismo de cooperación y visibilización fue concebido para estrenarse al aire a mediados del segundo semestre de 2018 con una frecuencia de emisión quincenal a mensual. 
encuentros y actividades de carácter científico, académico y de extensión; se garantiza la continuidad de los CLEU aportando nuevas experiencias y propuestas de solución a los problemas relacionados con el entorno sociocultural universitario y su impacto social. ${ }^{15}$ Adicionalmente, fomenta la unidad e integración regional, propicia el intercambio y debate científico extensionista, promueve la difusión de información, acciones y buenas prácticas extensionistas de los demás miembros de la red a través de los medios de comunicación propios o al alcance de cada uno, favorece el desarrollo y formación del recurso humano en extensión universitaria y para ello impulsa la internacionalización de la extensión en toda la región, sustentada en estrategias de movilidad y desarrollo conjunto de programas y proyectos, entre otros.

En tanto, los miembros de la ULEU son los únicos a nivel regional en ofrecer un Plan de formación y capacitación certificable en extensión, proyección social, vinculación con el medio o vinculación con la sociedad de manera periódica; ello con el apoyo de los delegados y enlaces oficiales de la red junto a la realización de actividades nacionales o regionales de visibilización de la gestión y compromiso de la ULEU, entre otros. De esta manera es posible apreciar que la Unión cuenta con grandes aportes académicos, investigativos y en materia de políticas públicas, los cuales se ven reflejados, por ejemplo, en la producción académica publicada:

- Revista Identidad y Territorio (34 números a la fecha).

- Cuadernos de Extensión Universitaria de la Universidad Nacional de La Pampa (tres cuadernillos a la fecha).

- Biblioteca virtual de la ULEU.

- Glosario de términos que se utilizan en extensión universitaria.

- Biblioteca de Extensión Universitaria-BEU.

- Red de Observatorios y de Cátedras Abiertas de Extensión.

- Libros, entre ellos:

- La extensión universitaria "aportes para la construcción de la red de observatorios y Cátedras abiertas y/o libres".

- Integración docencia y extensión: Otra forma de aprender y de enseñar.

- Extensión: reflexiones para la intervención en el medio urbano y rural.

- Los caminos de la extensión en la universidad argentina.

- Los caminos de la extensión en América Latina y el Caribe.

- Los caminos de la extensión en la Universidad Nacional de la Pampa.

- Extensión crítica. Construcción de una Universidad en contexto: Sistematizaciones de experiencias de gestión y territorio de la Universidad Nacional de Rosario.

- Memorias de los congresos iberoamericanos.

Por otra parte, y retomando la línea de recorrido histórico, los diferente directivos y miembros de la ULEU determinaron con el tiempo la necesidad de organizarse mediante

15) Entendiendo el impacto social como proceso del análisis y tratamiento de las consecuencias sociales, tanto positivas como negativas, del desarrollo de los diversos proyectos extensionistas y servicios a la comunidad, lo cual permite dotarse de herramientas para la gobernanza, el liderazgo y la relación con las comunidades.

Para ello se tienen en cuenta: la caracterización, evaluación, seguimiento y gestión de las consecuencias y riesgos sociales de los proyectos sobre el entorno. Además, el análisis de las percepciones, inquietudes y expectativas de las mismas poblaciones y comunidades. 
comisiones de trabajo. Para ello crearon dentro de su estructura las siguientes:

- Comisión de formación y capacitación en extensión universitaria.

- Comisión para la implementación de observatorios de extensión universitaria (fusionada con la comisión de formación a partir de febrero de 2018).

- Comisión de comunicación, que incluye la coordinación de la página web de la ULEU, la revista digital y redes sociales. ${ }^{16}$

- Comisión de políticas para el financiamiento de la extensión universitaria.

- Comisión de políticas para el financiamiento de la extensión universitaria.

- Comisión de sistematización de los archivos y la documentación de la ULEU.

Al respecto, vale la pena mencionar que la Comisión de formación y capacitación en extensión universitaria (reestructurada en 2015), fue propuesta con el fin de incrementar el trabajo de la red frente a la integración de las universidades y la capacitación en la materia de los diferentes agentes gestores extensionistas de los países miembros realizando las adecuaciones necesarias propias a cada región.

Gracias a su trayectoria, la ULEU ha alcanzado un mayor reconocimiento como espacio de intercambio, reflexión y producción de conocimiento extensionista a nivel latinoamericano, lo que le permite consolidarse como red internacional que, además de agrupar otras redes regionales, garantiza el diseño de estrategias comunicativas de difusión y socialización para actividades-proyectos desarrollados en la materia. El impacto de ULEU genera, promueve, difunde e institucionaliza políticas de extensión universitaria, proyección social, vinculación con el medio o relación universidad-sociedad, lo cual redunda en el fortalecimiento de las universidades e instituciones de educación superior y aporta a una educación solidaria, real, actualizada y comprometida con las comunidades.

\section{La ULEU y la integración de las funciones universitarias}

Los procesos de integración de las funciones misionales universitarias (docencia, investigación y extensión) ha sido uno de los temas de constante reflexión y debate al interior de la ULEU, como un acto educativo a desarrollar y fortalecer para el crecimiento de la región. Ejemplo de ello son los títulos y ejes de trabajo de los congresos latinoamericanos desarrollados en 1998, 1999, 2009, 2011, 2013 y $2015 .{ }^{17}$ En esa medida, para la ULEU la integración de extensión universitaria es un proceso indispensable que conlleva a la mejora de los resultados académicos, sociales y ciudadanos de los países de la región, así como de las

16) http://www.uleu.org

http://www.uleu.org/uleu_wp/2015/08/31/revistas/

https://www.facebook.com/red.uleu

17) Año 1998: III Congreso Iberoamericano y del Caribe de Extensión Universitaria (eje: La articulación de las funciones de docencia-investigación-extensión). 1999: IV Congreso Iberoamericano y del Caribe de Extensión Universitaria (eje: Articulación de las funciones universitarias). 2009: X Congreso Iberoamericano de Extensión Universitaria-ExtenSo (eje: Prácticas integrales: articulación de Investigación, Enseñanza y Extensión). 2011: XI Congreso lberoamericano de Extensión Universitaria: "Integración Extensión, Docencia e Investigación para la inclusión y la cohesión social”. 2013: XII Congreso Iberoamericano de extensión universitaria: "La Integración de la docencia, la investigación y la extensión para la transformación social y el buen vivir”. 2015: XIII Congreso Iberoamericano de Extensión Universitaria (eje: Gestión integrada de la extensión en su vínculo con la docencia y la investigación). 
universidades y sus contextos territoriales. Trabajar en la integración de estas tres funciones es una oportunidad para repensar el sentido mismo de la educación, en la medida en que ello contribuye a los procesos de inclusión social, el fortalecimiento de las organizaciones de la sociedad civil y la articulación con los Estados, la creación y actualización de políticas públicas educativas.

Para quienes conforman la Unión Latinoamericana, los procesos de integración de funciones significan la búsqueda de nuevos conocimientos, nuevos caminos y alternativas desarrolladas de manera estratégica por diferentes actores que participan activamente en la construcción conjunta de agendas para la investigación, la academia y el crecimiento social. Es a partir de este diálogo de saberes que la ULEU propone crear espacios intersectoriales e interinstitucionales que trabajen en la producción de conocimientos orientados a los territorios, contextos sociales y productivos de las regiones en las cuales la Universidad genere la cercanía necesaria para alcanzar la apropiación social de los mismos. Vista de este modo, la integración de la docencia, investigación y extensión se convierte en eje fundamental para la transformación social.

Desde esta perspectiva, la extensión universitaria se visualiza como función sustantiva jerarquizada, con una clara incorporación curricular y reconocimiento académico que, adicionalmente, cuente con las asignaciones presupuestarias necesarias, los equipos interdisciplinarios y reconocimientos del caso que permitan ir más allá de un proceso de transferencia académica o tecnológica.

Para esta red latinoamericana, al trabajar la integralidad de las funciones universitarias, las universidades asumen su compromiso social y promueven la democratización del saber, del conocimiento y de la cultura en diálogo permanente con la sociedad, validan el conocimiento transmitido y creado en el marco de diferentes realidades de los países, brindando desarrollo académico, científico y tecnológico e interactuando con los Estados y diferentes actores sociales y socioproductivos.

Ahora bien, al integrar la docencia y la extensión con un enfoque dialógico-crítico (característico de la ULEU), se promueve una formación humanística de los profesionales, ciudadanos críticos y comprometidos. Se favorecen las nuevas redes conceptuales y los diferentes lenguajes y metodologías pensadas desde la articulación de los contenidos que provienen de resultados de investigación y docencia cuyo origen radica en las problemáticas del entorno mismo. De esta manera, la articulación de tales funciones universitarias beneficia los procesos de formación al poner en escena la relación entre las necesidades de la sociedad y el potencial transformador de la enseñanza-aprendizaje.

Por su parte, la integración de extensión e investigación, igualmente bajo una óptica dialógico-crítica contribuye, entre otros aspectos, a que los contenidos de las investigaciones desarrolladas en la universidad, respondan a los estímulos recibidos a partir de los previos acercamientos al entorno y a la integración de algunas de sus problemáticas. Trabajar de manera articulada, según la ULEU, es lograr un desarrollo científico y tecnológico progresivo y para todos, es promover proyectos de investigación sobre problemáticas socialmente relevantes, definidas en forma participativa con actores universitarios y no universitarios, este último aspecto bastante significativo para la ULEU.

La extensión universitaria vista de esta manera posibilita la problematización y profundización de diversas áreas temáticas, desde las cuales el análisis crítico, la indagación y 
reflexión actúan como herramientas de transformación a favor de un proceso de formación integral soportado en las realidades de la sociedad.

Retomando las reflexiones de los miembros de la red nacional de extensión universitaria de Colombia (integrante de la ULEU):

"la extensión, debe ser vista en su dimensión formativa, dado que posibilita escenarios que fortalecen la formación integral y que a su vez permiten una acción transformadora en la sociedad, en el cumplimiento de la función social de la Universidad. En ese sentido, la extensión está ligada a los programas curriculares, así como, a proyectos de transformación en los cuales el ejercicio académico e investigativo se vincula a las realidades del país para incidir en procesos de cambio. Es entonces, a la luz de la integración de los tres ejes misionales de las IES, que cada uno de dichos procesos presenta también elementos cuya articulación genera una integración y convergencia entre las acciones que se desarrollan para responder a las necesidades y oportunidades tanto internas como externas". (ASCUN, 2018:29)

Además, la ULEU está convencida de que la articulación entre la docencia y la investigación se da en la medida en que la investigación atiende las problemáticas abordadas desde la realidad y su complejidad generando conocimiento tecnocientífico, multi, trans e interdisciplinario y en la transferencia de este conocimiento, pero también la extensión es interacción e integración cuando sus resultados retroalimentan las funciones de docencia e investigación a fin de que, a partir de las experiencias y conocimientos adquiridos del ejercicio práctico, se traduzcan en nuevas líneas de investigación o en la incorporación de nuevos temas en los programas curriculares y prácticas en la docencia.

Durante la articulación de las tres funciones sustantivas, es posible identificar tres tipos de saberes esenciales sin los cuales sería casi imposible realizar una gestión pertinente de la extensión o proyección social: el saber académico procedente de la universidad, el saber estructurado originado en el sector productivo, y el saber popular emanado de las comunidades. Es entonces a partir de esta articulación de funciones y saberes que se posibilita, produce y alcanza el desarrollo en de la región.

En suma, para la ULEU es importante entender que la extensión no se realiza únicamente durante tiempos extra curriculares o de manera aislada sino que, por el contrario, alcanzar la integración de las tres funciones misionales universitarias es trabajar por la pertinencia de la educación superior en el ámbito nacional e internacional generando una verdadera transformación social.

\section{A manera de cierre}

La extensión universitaria, proyección social, relación universidad-sociedad implica, entre otros aspectos, poner al servicio de las comunidades las capacidades y los conocimientos adquiridos o generados a través de la academia, y para ello la identificación de posibles asociaciones consolidadas como redes académicas universitarias que trabajan a favor de la educación es apenas una manera de internacionalizar tanto la educación como las universidades e instituciones que la realizan. En esa medida, fortalecer a la extensión universitaria como una manera de investigar, enseñar, aprender y producir conocimiento desde un con- 
texto real es sin duda alguna una de las tareas que debe continuar afrontando Latinoamérica y para ello el papel que desempeña la ULEU en la región es fundamental.

La promoción de la extensión desde los diferentes ámbitos y regiones es entonces una de las estrategias a través de las cuales esta red, como espacio de cooperación y reflexión, aporta a la integración de los países abriendo las fronteras y propiciando relaciones de solidaridad a favor del crecimiento de la educación superior.

Por otra parte, identificar, gestionar, patrocinar y ejecutar proyectos extensionistas articulados con la docencia y la investigación a nivel latinoamericano y caribeño seguirá siendo una labor ineludible dentro de las agendas regionales de los gobiernos, las universidades y las diferentes redes de extensión. Pero para que esto continúe siendo una realidad es necesario que los diversos escenarios de cooperación, reflexión y diálogo académico (a manera de asociaciones y redes universitarias) hagan presencia como actores que asesoran y coadyuvan a los gobiernos en la creación e implementación de políticas al respecto.

La ULEU no solo ha sido una de las primeras redes regionales en generar políticas o trabajar a favor de la extensión, sino que también ha logrado su internacionalización, evidenciando y compartiendo la gran variedad de experiencias existentes. Para ello ha democratizado el conocimiento, ha trazado los caminos enfatizando en la reflexión dialógico-crítica permanente y necesaria para la relación de la academia y las comunidades. De allí quedan múltiples enseñanzas, aprendizajes y opciones al alcance de todos.

En consecuencia, para muchos, el respaldo, la orientación y la formación recibida a través de la ULEU han sido y seguirán siendo indispensables en los procesos de institucionalización y jerarquización de la extensión universitaria en cada una de las universidades en que se encuentran. Con ULEU, recorrer nuevos caminos es mucho más sencillo y alentador, pues existe una interrelación de actores con los cuales construir y caminar juntos.

Pero quizás algunos de los mayores aportes y retos que enfrenta ULEU radiquen en la unificación de criterios relacionados con la temática que la convoca, la producción de conocimientos y la construcción de indicadores a favor del seguimiento y medición del impacto en extensión.

No cabe duda de que la apuesta de esta red por la creación e implementación regional de procesos de formación y capacitación en extensión para docentes, gestores y extensionistas en general de manera certificable es uno de los mayores aportes tanto para la función universitaria como para quienes la realizan a lo largo y ancho del Caribe y América Latina. Como decía Jorge Castro, ${ }^{18}$ el mayor de los retos es: ;Ser docentes, investigadores y extensionistas! Una bandera que ha orientado 20 años de trabajo de la ULEU.

18) Jorge Orlando Castro (1962-2017): nacido en La Plata, Argentina, fue reconocido como uno de los abanderados y grandes referentes latinoamericanos en extensión universitaria. Estudió Periodismo, fue secretario de Extensión, asesor de Asuntos Latinoamericanos, docente, presidente de la Comisión de Enseñanza e Investigación en Argentina. Director de Comunicación de la ULEU, director de la carrera de periodismo de la UNDAV y conductor del programa radial Comunicación en red de la Red de Carreras de Comunicación de Argentina entre otros.

Generador de redes extensionistas en Argentina, Latinoamérica y el Caribe, quien dejó el legado de la extensión dialógico-crítica, así como la importancia de articular la academia a los contextos sociales, rompiendo paradigmas e ideas de una universidad que "fabrica profesionales". Promovió la importancia de pensar las realidades y caminarlas con los estudiantes para poder entenderlas y transformarlas, buscó que la "universidad no llegara a los barrios, sino que los barrios fueran parte de la universidad", desde una mirada dialógica de la extensión que siempre defendió y desarrolló. Falleció en 2017 a los 54 años tras sufrir un infarto. 


\section{Referencias bibliográficas}

Biblioteca Digital de Extensión Universitaria BEÚ (2017). "Glosario de términos que se utilizan en extensión universitaria". Recuperado de http://beu.extension.unicen.edu.ar/xmlui/handle/123456789/32 (14/06/2018)

Chacín, B, González, M. \& Torres, Y. (2007). Crítica a la generación del conocimiento en la extensión universitaria: aproximación a un protocolo de investigación innovativa. Universidad Pedagógica Experimental Libertador, Venezuela.

CRES (2008). Declaración de la Conferencia Regional de Educación Superior en América Latina y el Caribe. Cartagena, Colombia: UNESCO- IESLAC.

Congreso de Colombia (1992). "Ley 30 de 1992, artículo 120”. Recuperado de https://www.cna.gov.co/1741/ articles-186370_ley_3092.pdf (13/06/2018).

Declaración de Caracas (1999). En: IV Congreso Iberoamericano y del Caribe de Extensión Universitaria. Universidad Pedagógica Experimental Libertador, Vicerrectoría de Extensión, Caracas, Venezuela (pp.32).

IESLAC (2018). "Redes de Educación Superior". Recuperado de http://www.iesalc.unesco.org.ve/index. php?option=com_content\&view=article\&id=2372\&ltemid=829\&lang=es (13/06/2018).

Knight, J. (2010). Internacionalización de la Educación Superior: Nuevos desarrollos y Consecuencias No Intencionada. En: Boletín IESALC informa de Educación Superior. Recuperado de http://www.iesalc.unesco. org.ve/index.php?option=com_content\&view=article\&id=2418\%3Ainternacionalizacion-de-la-educacion-superior-nuevos-desarrollos-y-consecuencias-no-intencionadas\&catid=126\%3Anoticias-pagina-nueva\&ltemi$\mathrm{d}=712$ \&lang=es (12/06/2018).

Red Nacional de Extensión Universitaria. (2018). Política de Extensión: por una universidad comprometida con el país. ASCUN. Bogotá, Colombia.

Unión Latinoamericana de Extensión Universitaria ULEU (1996). "Quienes somos-Declaración final”. Recuperado de http://www.uleu.org/uleu_wp/2012/05/20/quienes-somos-2/ (30/05/2018).

(2012). "Quienes somos". Recuperado de http://www.uleu.org/uleu_wp/2012/05/20/quienes-somos-2/ (30/05/2018).

(2014). "Actas-acuerdos-declaraciones". Recuperado de http://www.uleu.org/uleu_wp/2014/08/31/ actas-acuerdos-declaraciones/ (30/05/2018). 